\title{
Social Networks, Ethnicity, and Entrepreneurship
}

\section{Citation}

Kerr, William R., and Martin Mandorff. "Social Networks, Ethnicity, and Entrepreneurship." Harvard Business School Working Paper, No. 16-042, October 2015. INBER Working Paper Series, No. 21597, September 2015.)

\section{Permanent link}

http://nrs.harvard.edu/urn-3:HUL.InstRepos:23490132

\section{Terms of Use}

This article was downloaded from Harvard University's DASH repository, and is made available under the terms and conditions applicable to Open Access Policy Articles, as set forth at http:// nrs.harvard.edu/urn-3:HUL.InstRepos:dash.current.terms-of-use\#OAP

\section{Share Your Story}

The Harvard community has made this article openly available.

Please share how this access benefits you. Submit a story.

\section{Accessibility}




$$
\text { H A R VAR D B US INESS SCHOOL }
$$

\section{Social Networks, Ethnicity, and Entrepreneurship}

William R. Kerr

Martin Mandorff

Working Paper 16-042 


\section{Social Networks, Ethnicity, and Entrepreneurship}

William R. Kerr

Harvard Business School

Martin Mandorff

Swedish Competition Authority

Working Paper 16-042 


\title{
Social Networks, Ethnicity, and Entrepreneurship
}

\author{
William R. Kerr \\ Martin Mandorff* \\ Harvard University and NBER Swedish Competition Authority
}

September 21, 2015

\begin{abstract}
We study the relationship between ethnicity, occupational choice, and entrepreneurship. Immigrant groups in the United States cluster in specific business sectors. For example, Koreans are 34 times more likely than other immigrants to operate dry cleaners, and Gujarati-speaking Indians are 108 times more likely to manage motels. We develop a model of social interactions where non-work relationships facilitate the acquisition of sector-specific skills. The resulting scale economies generate occupational stratification along ethnic lines, consistent with the reoccurring phenomenon of small, socially-isolated groups achieving considerable economic success via concentrated entrepreneurship. Empirical evidence from the United States supports our model's underlying mechanisms.
\end{abstract}

Key words: entrepreneurship, self-employed, occupation, ethnicity, immigration, networks.

JEL codes: L26; D21, D22, D85, F22, J15, L14, M13.

${ }^{*}$ Comments are appreciated and can be sent to wkerr@hbs.edu. We thank Gary Becker, Ola Bengtsson, Gustaf Bruze, Dennis Carlton, Barry Chiswick, Matthew Gentzkow, Emil Iantchev, Svante Janson, Mini Kaur, Steven Lalley, Ben Mathew, Andriy Protsyk, Jesse Shapiro, Rachel Soloveichik, Chad Syverson, Robert Topel and Nick Wormald and seminar participants for very valuable comments. We thank Meir Brooks and Rahul Gupta for excellent research support. This paper is a revised version of a paper initially prepared for The Economics of Entrepreneurship: Bringing the Entrepreneur Back into Economics conference in Venice, Italy, during July 2015. The theory section of this paper draws heavily from Mandorff's Ph.D. Dissertation at the University of Chicago. Financial support from the Marcus Wallenberg Foundation, the Jan Wallander and Tom Hedelius Foundation, the Esther and T.W. Schultz Dissertation Fellowship, the Markovitz Dissertation Fellowship, the Kauffman Foundation, and Harvard Business School is gratefully acknowledged. 


\section{Introduction}

Minority groups often concentrate in specific occupations and with a bent towards entrepreneurship. Kuznets (1960) observes that "all minorities are characterized, at a given time, by an occupational structure distinctly narrower than that of the total population and the majority." While the particular ethnic group and the particular occupation in which the group specializes varies over time and with location, specialization as a rule occurs in ethnic groups that are socially cohesive and in occupations where self-employment is the norm. Prominent examples of such ethnic specializations are the Jewish merchants in Medieval Europe, the Chinese launderers in early twentieth century California, and more recently the Korean dry cleaners and the Indian motel owners in the United States.

Occupational choice and entrepreneurship are correlated with ethnicity even when accounting for differences in demographic characteristics and other quantifiable attributes. The generating mechanism behind these self-employment clusters must therefore involve sorting based on unobservable characteristics that are correlated with ethnicity. While individual characteristics can be linked to ethnicity because of differences in the social and legal status or the unique historical experiences of each ethnic group, choice behavior can also generate group differences. Variation in occupational structure need not always result from systematic differences between ethnic groups, but as we show in this paper, occupational choice and entrepreneurship can also be a stratifying force in itself. ${ }^{1}$

We contribute to the understanding of group differences by developing a theory of how economic behavior can lead to stratification. This theory is related to the concept of ethnic capital as developed by Borjas (1992, 1995), but it emphasizes choice and interactions more explicitly than does the standard treatment of ethnic capital. By tying together occupational choice with social interactions, entrepreneurship and skill acquisition, we show how social relationships in efficient markets can generate long-run occupational stratification, and as a consequence lead to persistent differences in economic outcomes between groups. We also demonstrate how occupational specialization is especially likely to appear in small groups, and, in direct contrast to the effects of discrimination in the marketplace as analyzed by Becker (1957), we show how social interactions can sometimes favor minority groups over the majority.

Beginning with occupational concentration, minority groups that successfully specialize in business activities appear in many economies throughout history, and traditional explanations focus on the temporary nature of some stays or explicit restrictions

\footnotetext{
${ }^{1}$ In the context of this paper, the terms self-employed, entrepreneur, and business owner have very similar meanings and are used interchangeably. In a similar manner, it will become evident that the ethnic specialization we depict can be thought of in terms of occupational or industry concentration (e.g., concentration of self-employment for the taxi cab industry).
} 
on activity. ${ }^{2}$ These earlier explanations do not apply very well to the United States today, however, and yet we continue to observe many specialized ethnic groups that have settled permanently. Prominent examples include ethnic groups from Korea, Greece, India, and the Middle East. This concentration can be very sharp, with a striking $45 \%$ of adult Korean males being self-employed, in contrast to $15 \%$ of the adult male immigrant population as a whole. Furthermore, different groups cluster in different business sectors: Yemeni are 75 times more likely to own grocery stores than other immigrants, and Gujarati-speaking Indians are 108 times more likely to operate motels. Likewise, Greeks concentrate in the restaurant sector, and Middle Eastern immigrants cluster in grocery stores and liquor stores. We consider in this paper how social interactions can prompt this regular feature across many diverse groups.

Turning to social interactions and skill acquisition, we use the term "social interaction" here to describe interaction that takes place outside of work: family gatherings, religious and cultural functions, meetings with friends, and similar. A considerable literature analyzes the importance of social interactions for economic behavior outside of the workplace (e.g., Glaeser et al., 1996; Bertrand et al., 2000; Glaeser and Scheinkman, 2002). A smaller literature looks at the role of social interactions for workplace outcomes. In the context of occupational choice, Granovetter (1973) finds that jobs often are found through referrals, and that these tend to come from more casual acquaintances, so-called "weak ties." Montgomery (1991) provides a comprehensive survey of the incidence of jobs found through referrals, and Durlauf and Fafchamps (2006) and Durlauf and Ioannides (2010) are broader reviews.

Skill acquisition is potentially an even more important aspect of relationships in determining occupational choice. Private information and tacit knowledge are instrumental to productivity in many occupations. For example, self-employed entrepreneurs in the small business sector are their own managers, and they must rely on their own judgment to make business decisions. Skills in this sector may come in the form of knowledge of how to start or take over a business; information about market conditions (e.g., demand levels, pricing); knowledge of how to establish supplier, customer,

\footnotetext{
${ }^{2}$ Examples include the Jews in Medieval Europe and around the Mediterranean, the Armenians in the Ottoman Empire, the Jains and the Parsis in India, the Lebanese in West Africa, the Indians in East Africa, the Japanese in South America, and the Chinese in Southeast Asia and the Caribbean. Several works in sociology analyze this phenomenon, with Blalock (1967) applying the term "middleman minorities" to these groups. Bonacich (1973) put forward what is known as the "sojourner theory," explaining specialization as the outcome of temporary residence; more recently, Botticini and Eckstein (2005) study path dependence and Jewish occupational specialization, which they propose is the outcome of a religious literacy requirement. More broadly, Aldrich and Waldinger (1990) review the sociology literature on ethnic entrepreneurship, and Sowell (1981) analyzes the role of culture more generally. Related classic work also includes Milgram (1967), Light (1977), Thernstrom (1980), Landa (1981), Milgrom et al. (1990), Melton (1990), Sowell (1996), Cohen (1997), Greif (1993), and Greif et al. (1994).
} 
and employee relationships; and insights into legal and tax-related issues. These skills are valuable and cannot be instantaneously transferred from one entrepreneur to another. Chung and Kalnins (2006) further trace out resource access through ethnic networks in the case of Gujarati hotel owners.

Social interaction with people in the same industry can reduce the cost of skill acquisition. Industry information and professional advice can be exchanged at little or no time cost while attending a family gathering or a religious ceremony, and interaction can therefore be complementary to skill acquisition. ${ }^{3}$ This role of social interaction is difficult to measure directly since few datasets contain information about horizontal relationships such as friendship and extended family. Fairlie and Robb (2007) document from the Characteristics of Business Owners database that more than half of business owners have close relatives who are self-employed, and a quarter of business owners have worked for these relatives. Datasets linking vertically across generations are more common. Dunn and Holtz-Eakin (2000) find that the incidence of self-employment, controlled for other factors, doubles when an individual's parents are self-employed.

We unite these features by making an important distinction between market interaction and social interaction that is central to our analysis. The social interaction theory that we develop differs from the standard theory of discrimination. We analyze the case when groups are economically integrated but culturally isolated; groups are assumed to be exclusive in their social interactions, while fully participating in the market economy. In this case, no discrimination coefficient as in Becker (1957) taxes the market transactions between groups. To illustrate how market interaction can take place without social interaction, consider a scene from Shakespeare's The Merchant of Venice (Act 1, Scene III) depicting the social divide between the Christians and Jews in Renaissance Europe. Following a negotiation over a large loan to a Christian man who has always scorned him, the Jewish moneylender Shylock comments: "I will buy with you, sell with you, talk with you, walk with you, and so following; but I will not eat with you, drink with you, nor pray with you."

Both market interaction and social interaction generate stratification, but in different forms and with different economic consequences. Minorities are put at a disadvantage in industries where market interaction is important, and are consequently driven out of these sectors; a group speaking only a minority language would for example have a hard time competing in an industry such as academia. ${ }^{4}$ Discrimination

\footnotetext{
${ }^{3}$ The complementarity between social interaction and skill acquisition can be derived in several ways. First, if people derive utility from spending time in the presence of friends, mentoring friends may provide more utility than mentoring non-friends. Second, people spend significant time at social events, and business knowledge can diffuse among participants. Third, people may trust the reciprocity of friends and therefore share knowledge, expecting future favors in return.

${ }^{4}$ Market interaction can also generate specialization at the establishment level. For example, kitchen workers in the restaurant business might stratify along ethnic lines. The result is that each
} 
in the marketplace, whether in the form of outright prejudice or simply the inability to communicate in other languages, imposes greater economic cost on the minority than on the majority (Becker, 1957), just as a small country is more dependent on trade than a large country. ${ }^{5}$ This paper describes how social interactions can work in the opposite direction of market interactions. Social complementarities in industries where sector-specific skills are important can drive otherwise similar groups to specialize in different sectors, and these social complementarities can result in a favorable economic outcome for some minority groups. ${ }^{6}$

The next three sections formalize this conceptual structure. Section 2 develops a two-group, two-sector model of identical agents where social interactions are random within groups and where social relationships and production are complementary in one sector. We characterize the efficient outcome and show that different groups should specialize in different sectors, with small groups having an absolute advantage in sectors where the complementarity between interaction and production is strongest. Section 3 characterizes the competitive equilibrium. We introduce dynamics to demonstrate how social interactions amplify initial group differences and result in long-run occupational specialization (Patel and Vella, 2013). We also show that under identical skill distributions for groups, mean earnings are positively related to a group's equilibrium level of specialization. Section 4 analyzes relationships in a social network where interactions are endogenously determined as the outcome of efficient matching. Relating social networks to employment is akin to Calvo-Armengol and Jackson (2004), who develop a social network model of job referrals that generates persistent employment differences. But while they take the social network as given, we derive the properties of a social network that is endogenously determined. We show that the results of the random interaction model in Section 2 are strengthened, provided that social relationships are not close substitutes to one another.

Section 5 analyzes the model's predictions using Census Bureau data for the United States in 2000. Entrepreneurial activities and social interactions are clearly correlated, but identifying interaction effects is notoriously difficult. Unobservable characteristics

establishment will have a homogenous workforce, but the ethnic composition at the industry level is not affected. Market interaction at the establishment level — such as in the restaurant example generates specialization at the establishment level, whereas market interaction at the industry level — such as in academia - generates specialization at the industry level.

${ }^{5}$ Similar results are derived in a model of random encounters by Lazear (1999), who analyzes the effects of group size on assimilation. If ethnicity were endogenous in the model developed in this paper, then assimilation pressures similar to those in Lazear (1999) would arise, although this could be counterbalanced by the economic benefits of belonging to a specialized minority group, as is made clear later on in this paper.

${ }^{6}$ The favorable economic outcome does not necessarily carry over to utility. Depending on the degree of endogeneity of social interaction, the overall situation for minority groups may still be worse than the overall situation for the majority. 
can give rise to the reflection problem described by Manski (1993). For example, since people have a proclivity for cuisine from their home country, Greek restaurateurs will sort into Greek restaurants and Chinese restaurateurs will sort into Chinese restaurants, independent of social relationships. This sorting mechanism is well-understood and very likely at work in some occupations. The interaction theory developed in this paper has particular implications, however, that are suitable for testing. First, if social interaction effects are important, specialization should appear strongest in groups that are socially isolated from the majority population. Case studies on successful entrepreneurial groups show that indeed these groups tend to be socially cohesive, as for example Indians in East Africa (Morris, 1956) and Lebanese in West Africa (Winder, 1962). Second, predictions exist for the earnings of self-employed groups.

We first provide extensive evidence of occupational clustering and entrepreneurship among ethnic groups, related to Patel and Vella (2013). We show how the size of groups and their social isolation, which we measure using in-marriage rates, strongly predict occupational concentration for entrepreneurs from the ethnic group. A 10\% decline in group size raises entrepreneurial concentration in one industry by $6 \%$, and a $10 \%$ increase in group isolation boosts concentration by $5 \%$. We show that these results are robust under many specification variants. These results could be biased, however, by omitted factors or reverse causality (e.g., occupational concentration leading to higher in-marriage rates). We consider two instrument variable specifications to address this issue. One approach uses the 1980 group sizes and in-marriage rates in the United States. Our second approach instruments US ethnic group size with the predictions from a gravity model for migration to the United States and instruments US in-marriage rates with those observed for the same ethnic group in the United Kingdom. These estimations confirm the OLS results. We finally provide earnings estimations consistent with the model's predictions.

Our final section concludes. Classic accounts of the nature of entrepreneurship emphasize in equal measure disruptive forces that entrepreneurs generate (Schumpeter, 1942, 1988) and their role in reducing price gaps and arbitrage opportunities (Kirzner, 1972, 1979). These theories rarely provide specific pressures or predictions for one group to become an entrepreneur versus another, except along defined traits like ability to navigate uncertainty (Knight, 1921), risk tolerance (Kihlstrom and Laffont, 1979), business acumen (Lucas, 1978), and skill mix (Lazear, 2005). Connections of entrepreneurship to migration status have been frequently noted but poorly explained. A central conclusion from this paper is that social interactions can generate grouplevel effects towards entrepreneurship and occupational choice that are important for explaining, today and in times past, why some populations show a greater tendency to self-employment, above and beyond other features that promote entry decisions. Further research needs to continue building out these connections from social net- 
works and occupational structures to entrepreneurship given the general applicability of these phenomena to many ethnic groups and their persistent roles in many cultures and economies.

\section{$2 \quad$ A Model of Specialization}

The theory in this paper consists of two fundamental building blocks. First, social interactions and production are complementary. Second, different social relationships are not close substitutes for one another. The former is dealt with in this section, while the latter is discussed extensively in Section 4 where relationships are analyzed in a social network with endogenous matching.

\subsection{Social Interaction as a Factor in Production}

Consider a population where everyone has equal innate ability, divided into two ethnic groups, $A$ and $B$. Group $A$ is in the minority, with a continuum of individuals of total mass $N_{A}$, and group $B$ is the majority, with a continuum of individuals of total mass $N_{B}$, where $N_{A}<N_{B}$. Members of $A$ and $B$ interact in the marketplace but are socially segregated and spend their leisure time separately. Assume that social interaction is random within groups; each person interacts with a representative sample of individuals in their own group only. ${ }^{7}$ This assumption of random interaction is relaxed in Section 4.

There are two occupations in our model: workers and entrepreneurs. Workers produce goods and entrepreneurs produce services in the form of selling the goods. Industry knowledge is important to entrepreneurs but not to workers, since entrepreneurs (as opposed to workers) are their own managers and have to rely on their own judgment when they make business decisions. When socializing during family gatherings and religious/cultural functions, entrepreneurs mentor each other and exchange industry knowledge and professional advice. ${ }^{8}$ The more an entrepreneur socializes with other entrepreneurs, the more knowledge is exchanged. Social interaction and production are therefore complementary in the entrepreneurial sector and entrepreneurial productivity increases with the number of friends and family members in that sector.

Define $X_{l}$ for $l \in\{A, B\}$ as the fraction of the population in group $l$ who are entrepreneurs. This fraction is referred to as the group's degree of specialization. Since social interaction is random within groups, a fraction $X_{l}$ of the friends and family

\footnotetext{
${ }^{7}$ The terms "representative sample" and "random sample" are used interchangeably. They coincide conceptually if the random sample is large enough, which is assumed to be the case.

${ }^{8}$ In addition to mentoring, social relationships can also improve the ability to extend credit. Social ties increase the cost of breaking a contract, adding social repercussions to economic and legal penalties.
} 
members of every individual in group $l$ are entrepreneurs as well. Denote individual entrepreneurial productivity in group $l$ as $\theta\left(X_{l}\right)$. Given that productivity increases when socializing with other entrepreneurs, it follows that:

Assumption 1a Entrepreneurial productivity increases in specialization: $\theta^{\prime}>0$.

This is the central component of the theory. Proceeding to specify a complete economic environment, denote $Q_{1}$ as the aggregate supply of services produced by entrepreneurs. Aggregate supply can be written as a function of the occupational distribution $\left(X_{A}, X_{B}\right)$ :

$$
Q_{1}\left(X_{A}, X_{B}\right)=X_{A} N_{A} \theta\left(X_{A}\right)+X_{B} N_{B} \theta\left(X_{B}\right)
$$

Since social interaction is assumed to play no productive role for workers, let the goods sector exhibit constant returns to scale with worker productivity normalized to one. Defining $Q_{0}$ as the aggregate supply of goods, write this as:

$$
Q_{0}\left(X_{A}, X_{B}\right)=\left(1-X_{A}\right) N_{A}+\left(1-X_{B}\right) N_{B}
$$

Moving from the supply-side to the demand-side, services and goods should be complementary enough to avoid the complications of multiple optima possibly generated by non-convexities. To simplify the exposition, let services and goods be perfect complements. Consumers then have Leontief preferences with the utility function:

$$
U\left(q_{0}, q_{1}\right)=\min \left(q_{0}, \frac{q_{1}}{v}\right)
$$

where $v>0$ is a preference parameter and $q_{0}$ and $q_{1}$ are individual consumption of goods and services, respectively.

\subsection{The Pareto Problem}

Since both commodities have unitary income elasticities, distributional aspects can be ignored when characterizing the efficient outcome. The problem simplifies to choosing an occupational distribution $\left(X_{A}, X_{B}\right)$ that maximizes a representative utility function $U\left(Q_{0}\left(X_{A}, X_{B}\right), Q_{1}\left(X_{A}, X_{B}\right)\right)$. A marginal analysis is inappropriate since this is a non-convex optimization problem. Consider instead the most specialized occupational distributions, where either as many individuals as possible in group $A$ or as many individuals as possible in group $B$ are entrepreneurs.

Figure 1 depicts the production possibilities for the two most specialized distribu-

tions. Define $V\left(X_{A}, X_{B}\right) \equiv \frac{Q_{1}}{Q_{0}}$ as the ratio of the supply of services to goods under the distribution $\left(X_{A}, X_{B}\right)$. Along the curve with the kink $V(1,0)$ in the figure, group $A$ specializes as entrepreneurs. Starting from a position with only workers furthest to 
the right, $A$ s are added to the entrepreneurial sector moving leftward along the x-axis. When reaching the kink $V(1,0)$, all $A$ s are entrepreneurs. Thereafter, continuing to move leftward, $B$ s are also added to the sector until when reaching $Q_{0}=0$, there are no more workers in the economy. Similarly, along the curve with the kink $V(0,1)$, group $B$ specializes as entrepreneurs. $B$ s are added moving leftward along the x-axis until reaching the kink $V(0,1)$, where all $B$ s are entrepreneurs. Thereafter also $A$ s are added until reaching $Q_{0}=0$.

\section{$\{$ Insert Figure 1$\}$}

The curve with minority specialization is above the curve with majority specialization, so long as the entrepreneurial sector is sufficiently small. A large fraction of $A$ s are entrepreneurs when the minority specializes, allowing minority entrepreneurs to socialize mostly within their own occupation, greatly improving productivity. The same is not true for the majority when they specialize, since even if a large fraction of entrepreneurs are $B \mathrm{~s}$, most $B$ s are nevertheless workers. As a result, majority entrepreneurs spend their time socializing with workers instead of with other entrepreneurs.

The argument can be generalized to show that minority specialization is Pareto efficient so long as the entrepreneurial sector is small enough. Perfect complementarity simplifies the problem of solving for the optimal allocation, since any bundle where goods and services are in the exact ratio $v$ of the Leontief preferences (3) is strictly preferable to all other bundles that do not include at least as much of both goods and services. The Pareto optimal distribution $\left(X_{A}, X_{B}\right)$ must therefore satisfy $v=$ $V\left(X_{A}, X_{B}\right)$. Define the total number of entrepreneurs in the population as $M \equiv$ $X_{A} N_{A}+X_{B} N_{B}$. It follows that:

Proposition 1 If $v \leq V(1,0)$, all entrepreneurs belong to minority $A$.

Proof: Take the distribution $\left(X_{A}, 0\right)$ where $X_{A}$ is such that $v=V\left(X_{A}, 0\right)$. This is feasible since $v \leq V(1,0)$. Assume by contradiction that it is not the uniquely efficient distribution. Then there exists an alternative distribution $\left(X_{A}^{\prime}, X_{B}^{\prime}\right)$ with $Q_{1}^{\prime} \geq Q_{1}$ and $Q_{0}^{\prime} \geq Q_{0}$. Given $Q_{0}^{\prime} \geq Q_{0}$ it follows that $M^{\prime} \leq M$, or equivalently, $X_{A}^{\prime} N_{A}+$ $X_{B}^{\prime} N_{B} \leq X_{A} N_{A}$, which implies $X_{A}^{\prime} \leq X_{A}$ and $X_{B}^{\prime}<X_{A}$, with $X_{A}^{\prime}<X_{A}$ if $X_{B}^{\prime}=0$. Manipulating the expression for $Q_{1}^{\prime}$ :

$$
\begin{aligned}
Q_{1}^{\prime} & =\left(M^{\prime}-X_{B}^{\prime} N_{B}\right) \theta\left(X_{A}^{\prime}\right)+X_{B}^{\prime} N_{B} \theta\left(X_{B}^{\prime}\right) \\
& <\left(M-X_{B}^{\prime} N_{B}\right) \theta\left(X_{A}\right)+X_{B}^{\prime} N_{B} \theta\left(X_{A}\right)=Q_{1}
\end{aligned}
$$

This contradicts $Q_{1}^{\prime} \geq Q_{1}$.

Consequently, the efficient outcome requires that a single group specializes as entrepreneurs, and importantly, which group specializes is not arbitrary. Minority specialization is more efficient since the minority's social isolation enables entrepreneurs 
in $A$ to socialize mostly within their own occupation. Proposition 1 implies that, for $v \leq V(1,0)$, the transformation curve and the curve with minority specialization in Figure 1 coincide. Group $A$ has absolute and comparative advantages as entrepreneurs.

If the demand for services is sufficiently great, however, then the minority is too small to satisfy demand by themselves. Instead, there is now a trade-off between few, highly-specialized minority entrepreneurs, or many unspecialized majority entrepreneurs. In the special case when $v=V(0,1)$, the demand for services is great enough for group $B$ to specialize completely. In this case minority involvement would just serve to dilute majority entrepreneurship, and the Pareto efficient solution is for $B$ s to specialize.

Corollary If $v=V(0,1)$, all entrepreneurs belong to the majority, $B$.

The proof is analogous to the proof of Proposition 1. As the corollary shows, the relationship between group size and productivity is not monotonic. Rather, the group with the absolute advantage is the group with a population size that most closely adheres to the size of the sector where social interaction and production are complementary. Other production possibilities generated by more unspecialized occupational distributions, such as $X_{A}=X_{B}$, are not displayed in Figure 1. Since some of these production plans could be above the two specialized curves in the Figure, the transformation frontier cannot be fully characterized at this stage. The production function must be restricted further to allow a complete characterization.

\subsection{Quality and Convex Productivity}

In addition to the quantity of friends that are entrepreneurs, the quality of these friends could also matter for productivity. Let individual productivity increase both in the quantity and in the average productivity of fellow entrepreneurs. Write this as:

$$
\theta=\phi+\delta X_{l} \bar{\theta}
$$

where $\phi>0$ is a productivity term, $0<\delta<1$ is a social multiplier, $X_{l}$ is the fraction of entrepreneurs in group $l$, and $\bar{\theta}$ is the average productivity of these entrepreneurs. Solving for equilibrium productivity by setting $\theta$ equal to $\bar{\theta}$, individual productivity is a function:

$$
\theta\left(X_{l}\right)=\frac{\phi}{1-\delta X_{l}}
$$

It follows that productivity is convex in the degree of specialization, when taking both the quantity and the quality of interaction into account. ${ }^{9}$ With this result in mind,

\footnotetext{
${ }^{9}$ This specification highlights the differences from a standard interaction model. The standard model is generally specified so that individual productivity is a function of a group-specific term $\phi$ and the discounted mean of the group, $\delta \bar{\theta}$. Solving $\theta=\phi+\delta \bar{\theta}$, interaction exacerbates the difference in $\phi$ across groups, $\theta=\frac{\phi}{1-\delta}>\phi$, but the degree of specialization $X_{l}$ has no effect on productivity.
} 
assume for now that productivity is indeed convex.

Assumption 1B Productivity is convex in specialization: $\theta^{\prime \prime}>0$.

Assumption 1B is unnecessary for the results in the next sections, but it is useful now to allow a full characterization of the efficient solution without having to resort to explicit functional form. Convex productivity gives the following result:

Lemma If productivity is convex, both groups never work in both sectors.

Proof: Assume by contradiction that an efficient distribution $\left(X_{A}, X_{B}\right)$ exists where $0<X_{l}<1$ for $l=\{A, B\}$. Consider a marginal change $\epsilon$ in the ethnic composition of entrepreneurs while holding fixed the overall number of entrepreneurs $M$ (and therefore also the supply of goods). Taking the derivative of $Q_{1}$ with respect to $\epsilon$, and evaluating it at $\epsilon=0$ :

$$
\frac{\partial Q_{1}}{\partial \epsilon}\left(X_{A}+\frac{\epsilon}{N_{A}}, X_{B}-\frac{\epsilon}{N_{B}}\right)=\theta\left(X_{A}\right)+X_{A} \theta^{\prime}\left(X_{A}\right)-\theta\left(X_{B}\right)-X_{B} \theta^{\prime}\left(X_{B}\right)
$$

Since $\left(X_{A}, X_{B}\right)$ is efficient, and since $X_{l}$ is interior, this derivative has to be zero. ${ }^{10}$ But with convex productivity the derivative is zero only at $X_{A}=X_{B}$, which is the global minimum. This contradicts efficiency.

The efficient economy aims for maximum ethnic homogeneity in entrepreneurship. Ruling out that both groups work in both sectors implies that only the specialized distributions along the two curves depicted in Figure 1 could possibly coincide with the transformation frontier. The shape of the entire transformation frontier can therefore be deduced by tracing out the maximum of the two curves in that Figure.

Proposition 2 If productivity is convex, there is a cutoff value $v^{*}$ such that for $v<v^{*}$, the minority specializes as entrepreneurs, whereas for $v>v^{*}$, the majority specializes.

Figure 2 shows how the degree of specialization varies with the size of the entrepreneurial sector, as governed by $v$, and the cutoff value $v^{*}$ for primary group specialization.

\section{$\{$ Insert Figure 2\}}

The greater the value of $v$, the greater is the demand for services and the more people work in the entrepreneurial sector. As the sector increases in size in Figure 2, the interaction externality generates a characteristic discrete jump from one type of equilibrium to another. At the point $v^{*}$, where many from group $B$ have also joined the entrepreneurial sector, the economy abruptly moves from minority specialization to majority specialization.

\footnotetext{
${ }^{10}$ If the derivative is nonzero, then the supply of services could increase while keeping the supply of goods constant. By subsequently increasing the number of workers marginally, a Pareto improvement is feasible, thus contradicting efficiency.
} 


\subsection{The Case of Non-Convex Productivity}

Finally, to see that convexity is needed for the Lemma on ethnic homogeneity to hold, consider a non-convex production function where a threshold fraction must work as entrepreneurs for interaction to have value: $\theta>0$ if $X_{l} \geq b$ and zero otherwise. This specification violates the assumption that productivity is strictly increasing in the degree of specialization. Then, if the demand for services is so great that a single group cannot satisfy it entirely, $v>V(0,1)$, and if in addition $V(b, b)<v<V(b, 1)$, efficiency requires that both groups work in both sectors, contradicting the Lemma.

To see why, consider what would happen if one of the groups specialized completely. In this case the non-specialized group's degree of specialization would be positive but below $b$, causing entrepreneurs in that group to have zero productivity. If, however, the occupational distribution was unspecialized instead, with $X_{A}=X_{B}$, then entrepreneurs in both groups would be as productive as those in the most productive group were under the alternative. Clearly this would be Pareto superior, contradicting the Lemma. This

special case shows how the Lemma fails for non-convex productivity, and how in this case the qualitative features of specialization will depend on specific functional form assumptions. Recall however that the results for both $v \leq V(1,0)$ and $v=V(0,1)$ are more general and apply both for convex and non-convex productivity.

\subsection{Skill-Specificity and Multi-Sector Extension}

The two-sector model can be directly applied to data if entrepreneurial skills are sufficiently general to encompass all forms of entrepreneurial activity: if, for example, operating a dry cleaning shop requires similar skills as operating a motel or a liquor store. If skills are more sector-specific, then a multisector framework is more appropriate. Although we do not develop a multi-sector model here, similar principles apply as in the two-sector model. In some special cases the efficient outcome is also intuitively similar to the two-sector model.

For example, consider an economy with two entrepreneurial sectors instead of just one, with equal demand for both services, and where there are two minority groups instead of just one, both equal in size. If the demand for entrepreneurial services is sufficiently small, then the efficient outcome is for one minority group to specialize in one entrepreneurial sector, and for the other minority group to specialize in the other sector. Which minority group specializes in which sector is arbitrary. In this multi-sector economy with sector-specific skills, otherwise-similar groups consequently specialize in different business sectors.

An interesting extension for future work is to include both general and specific skills in the same framework. In such a model of spillovers between sectors, it should be possible to derive stratification in overall entrepreneurial activity as well as stratification 
between different forms of entrepreneurship at the same time. This would correspond to the current situation in the United States, where groups like the Koreans are strongly clustered in a few business sectors, while at the same time being overrepresented in almost all other business activities as well.

\section{The Price Equilibrium}

The previous section characterized the efficient outcome. The focus now turns to the competitive outcome. An equilibrium analysis will yield two insights into how social interaction affects the occupational distribution. First, it shows how stratifying forces act to make groups more and more different, and second, how group earnings are positively related to the degree of specialization.

To see how social interaction works as a stratifying force, begin by introducing time into the analysis, with $t=0,1, \ldots, \infty$. Dynamics are built into the model by making the interaction effect work with a lag. Denote by $X_{l}^{t}$ the degree of specialization in period $t$ for group $l$, and let individual entrepreneurial productivity in period $t$ be a function $\theta\left(X_{l}^{t-1}\right)$. This one-period lag specification for the interaction effect could easily be generalized to a distributed lag. Interaction now effectively works as a form of social capital, with the group's occupational activities in the previous period benefiting individual productivity today. Let $p_{1}^{t}$ and $p_{0}^{t}$ be the prices of services and goods respectively. Entrepreneurial earnings are $y_{1, l}^{t}=p_{1}^{t} \theta\left(X_{l}^{t-1}\right)$ and worker earnings are $y_{0, l}^{t}=p_{0}^{t}$. Competitive occupational choice is straightforward to derive in this setting; defining the relative price of goods to services as $p^{t}=\frac{p_{0}^{t}}{p_{1}^{t}}$, an individual in group $l$ joins the entrepreneurial sector if:

$$
\theta\left(X_{l}^{t-1}\right) \geq p^{t}
$$

and favors being a worker if $\theta\left(X_{l}^{t-1}\right) \leq p^{t}$. Since individuals have identical skills, aggregate labor supply for group $l$ is discontinuous, with:

$$
X_{l}^{t}= \begin{cases}1 & \text { if } \theta\left(X_{l}^{t-1}\right)>p^{t} \\ {[0,1]} & \text { if } \theta\left(X_{l}^{t-1}\right)=p^{t} \\ 0 & \text { if } \theta\left(X_{l}^{t-1}\right)<p^{t}\end{cases}
$$

Avoid for now the knife-edge unspecialized case where $X_{A}^{t-1}=X_{B}^{t-1}$. Since there is a single price of labor, $p^{t}$, at least one of the two groups $A$ and $B$ must then be in a corner:

$$
\left(X_{A}^{t}, X_{B}^{t}\right)=\left\{\begin{array}{lll}
\left(X_{A}^{t}=1,0<X_{B}^{t}\right) & \text { or }\left(X_{A}^{t} \leq 1, X_{B}^{t}=0\right) & \text { if } X_{A}^{t-1}>X_{B}^{t-1} \\
\left(0<X_{A}^{t}, X_{B}^{t}=1\right) & \text { or }\left(X_{A}^{t}=0, X_{B}^{t} \leq 1\right) & \text { if } X_{A}^{t-1}<X_{B}^{t-1}
\end{array}\right.
$$


In equilibrium, supply must satisfy (10) and production must meet demand so that markets clear. Because of perfect complementarity, meeting demand reduces to satisfying $v=V\left(X_{A}^{t}, X_{B}^{t}\right)$. The resulting equilibrium distribution is unique. To see why, take the case when group $l$ is more specialized than group $l^{\prime}$ in the previous period, with $X_{l}^{t-1}>X_{l^{\prime}}^{t-1}$. Given that at least one of the two groups must be in a corner according to (10), the equilibrium distribution must either be of the type $\left(X_{l}^{t}, 0\right)$ or of the type $\left(1, X_{l^{\prime}}^{t}\right)$. Since the function $V$ is strictly increasing in both arguments, it follows that $V\left(1, X_{l^{\prime}}^{t}\right)>V\left(X_{l}^{t}, 0\right)$. Only one distribution can consequently make $V$ equal to $v$.

The equilibrium distribution is therefore uniquely determined by the distribution in the previous period. Continuing to avoid the knife-edge unspecialized case, define a function $\phi$ that maps every previous distribution into a new distribution:

$$
\left(X_{A}^{t}, X_{B}^{t}\right)=\phi\left(X_{A}^{t-1}, X_{B}^{t-1}\right)
$$

Next, proceed to characterize stationary equilibrium distributions. Like other equilibrium distributions, stationary distributions must satisfy (10) and must meet demand. Following the same argument as above, based on $V$ being strictly increasing in both arguments, it follows that there is a stationary equilibrium where each of the two groups specialize. Denote the stationary distribution as $\left(X_{A}^{A}, X_{B}^{A}\right)$ when the minority specializes, and the stationary distribution as $\left(X_{A}^{B}, X_{B}^{B}\right)$ when the majority specializes.

\section{$\{$ Insert Figure 3$\}$}

Finally, returning for a moment to the unspecialized knife-edge case where $X_{A}^{t-1}=$ $X_{B}^{t-1}$, this type of initial condition is of measure zero and therefore not elaborated on. Note only that since $V$ is strictly increasing in both arguments, there can only be one such stationary unspecialized equilibrium distribution. Denote that equilibrium distribution as $\left(X_{A}^{U}, X_{B}^{U}\right)$. In the unspecialized case, although there is only one stationary equilibrium, the uniqueness of equilibria no longer applies. To summarize, there are consequently three stationary equilibrium distributions: two specialized, $\left(X_{A}^{A}, X_{B}^{A}\right)$ and $\left(X_{A}^{B}, X_{B}^{B}\right)$, and one unspecialized, $\left(X_{A}^{U}, X_{B}^{U}\right)$. Figure 3 above shows the two specialized equilibria, as well as the knife-edge equilibrium, when $v$ is less than $V(1,0)$.

\subsection{Occupational Stratification}

The following section shows that the dynamic system in (11) converges to a stationary specialized equilibrium, so long as the interaction externality is not too strong. ${ }^{11}$ Consider what happens to the aggregate production of entrepreneurial services when

\footnotetext{
${ }^{11}$ This section only deals with unspecialized initial conditions, which establishes convergence on measure one.
} 
one (infinitesimal) person in group $l$ joins the entrepreneurial sector. First, aggregate production increases by an amount equal to the individual productivity of that person, $\theta\left(X_{l}\right)$. In addition, all other entrepreneurs in group $l$ benefit from the interaction externality when socializing with this entrepreneur. Individual productivity therefore increases by $\frac{1}{N_{l}} \theta^{\prime}\left(X_{l}\right)$ for all $X_{l} N_{l}$ entrepreneurs in group $l$. Consequently, the internalized effect on aggregate production of one person joining the entrepreneurial sector is $\theta\left(X_{l}\right)$, and the external effect is $X_{l} \theta^{\prime}\left(X_{l}\right)$. Assume that the external effect is smaller than the internal effect. ${ }^{12}$

Assumption 2 The internal effect dominates: $\theta^{\prime}\left(X_{l}\right) X_{l}<\theta\left(X_{l}\right)$.

This condition is satisfied if productivity is concave in $X_{l}$, but it also holds for some convexity as long as $\theta(0)>0$. To see why the assumption is needed for the system to be stable, consider the extreme case when group $A$ has no mass at all, with $N_{A}=0$. Since the derivative of $V$ with respect to $X_{A}^{t}$ is zero in this case, group $A$ can be ignored altogether in the general equilibrium analysis. There is then a single stationary level of specialization for group $B$; denote this value as $X_{B}^{*}$.

Consider a perturbation in period $t$ so that the majority starts out with too many entrepreneurs, $X_{B}^{t}>X_{B}^{*}$, shown in Figure 4 below. Such a deviation boosts the interaction effect in period $t+1$ relative to the stationary equilibrium, $\theta\left(X_{B}^{t}\right)>\theta\left(X_{B}^{*}\right)$. With perfect complementarity, the supply of both goods and services must therefore increase relative to their stationary equivalents. Increasing the production of goods requires an increase in the number of workers, and consequently, a decrease in the number of entrepreneurs to below the stationary value $X_{B}^{*}$. With fewer entrepreneurs in period $t+1$ than the stationary number of entrepreneurs, the tables turn in period $t+2$, so that the interaction effect now is reduced to below that in the stationary equilibrium. Reducing the production of both goods and services in period $t+2$ in response, the number of workers in period $t+2$ has to decrease and the number of entrepreneurs has to increase relative to the stationary equilibrium. These reversals repeat every period in cobweb-style dynamics. ${ }^{13}$

\section{$\{$ Insert Figure 4$\}$}

The question of whether the system is stable reduces to whether the number of entrepreneurs in period $t+2$ is less than the number of entrepreneurs in period $t$, so that the degree of specialization in group $B$ gets closer and closer to the stationary value $X_{B}^{*}$ over time. Using the derived direction of the change in the production of services,

\footnotetext{
${ }^{12}$ We thank Rachel Soloveichik for this interpretation of Assumption 2.

${ }^{13}$ The flip-flopping character of the equilibrium distribution is a result of the one-period lag specification for the interaction effect. The occupational distribution would change more gradually with a more general specification allowing for distributed lags.
} 
$Q_{1}^{t+1}>Q_{1}^{t+2}$, this latter inequality can be equivalently expressed, after multiplying and dividing the left-hand side by $X_{B}^{t}$, and dividing both sides by $X_{B}^{t+1} N_{B}$, as:

$$
X_{B}^{t} \frac{\theta\left(X_{B}^{t}\right)}{X_{B}^{t}}>X_{B}^{t+2} \frac{\theta\left(X_{B}^{t+1}\right)}{X_{B}^{t+1}}
$$

Given that productivity is not too convex, as stipulated by Assumption 2, it follows that $\frac{\theta\left(X_{l}\right)}{X_{l}}$ is strictly decreasing in $X_{l}$. Since $X_{B}^{t}>X_{B}^{t+1}$, equation (12) then establishes that $X_{B}^{t}>X_{B}^{t+2}$. This proves convergence and the stability of group $B$ 's degree of specialization around $X_{B}^{*}$.

Having established stability in the case of $N_{A}=0$, the same example also serves to show how the stratifying force comes into play. Let group $B$ be in its stable state, with $X_{B}^{t}=X_{B}^{*}$, and perturb the minority's occupational distribution so that $X_{A}^{t}>X_{B}^{*}$. Since group $B$ is so much greater in size than group $A$, the former is unaffected by the perturbation and the price continues to be locked in at $p^{t+1}=\theta\left(X_{B}^{*}\right)$. The interaction effect in period $t+1$, generated by the perturbation in period $t$, then results in everyone in group $A$ becoming more productive as entrepreneurs than as workers, with $\theta\left(X_{A}^{t}\right)>$ $p^{t+1}$. Group $A$ 's degree of specialization consequently jumps from $X_{A}^{t}$ to $X_{A}^{t+1}=1$, and the occupational distribution stays in this stratified state forever. This stratification result is extended in the appendix for the general case of any population size of the two groups, and it follows that for $l \in\{A, B\}$ and $l^{\prime} \in\{A, B\}$ :

Proposition 3 Initial differences result in long-run specialization: If group $l$ is more specialized than group $l^{\prime}$ initially, $X_{l}^{0}>X_{l^{\prime}}^{0}$, then group l specializes in the long run and the limiting distribution is $\left(X_{A}^{l}, X_{B}^{l}\right)$.

This also implies that the stationary unspecialized equilibrium $\left(X_{A}^{U}, X_{B}^{U}\right)$ is unstable. If the minority is slightly more specialized initially, then the economy converges to minority specialization $\left(X_{A}^{A}, X_{B}^{A}\right)$, and if the opposite is true, then the economy converges to majority specialization $\left(X_{A}^{B}, X_{B}^{B}\right)$. Over time, social segregation amplifies initial group differences.

\subsection{Initial Conditions and Multiple Groups}

Depending on the initial conditions, as is clear from Proposition 3, either of the two groups $A$ and $B$ can specialize as entrepreneurs. Social interaction amplifies initial differences, but it does not explain why they are there to begin with. The difference in group size has some implications for what initial conditions to expect, however.

Consider an economy with more than two groups. As before, the group that is most entrepreneurial initially will specialize in the long run. If the initial occupational distribution is subject to randomness, one of the smaller groups is likely to be the 
most specialized initially. To see why, let the initial distribution be generated by random draws, where each person becomes an entrepreneur with probability $\rho .{ }^{14}$ This probability structure results in the same expected initial degree of specialization for all groups, but since the population size varies across groups, the variance in the degree of specialization also varies. The smallest groups have the largest variance, and therefore, the smallest groups are most likely to exhibit the lowest and also the greatest initial degrees of specialization. Consequently, with the smallest groups the most likely to specialize initially, as interaction amplifies initial differences over time, the smallest groups are also the most likely to specialize in the long run.

\subsection{Heterogeneity and Earnings}

Social complementarities also have implications for earnings. To examine how interaction effects would show up in earnings data, it is necessary to move away from the framework of identical skills. Returning to a static environment, endow each person $i$ with entrepreneurial skills $s_{1}(i)$ and worker skills $s_{0}(i)$. Entrepreneurial earnings are now a function of both interactions and skills. Denote the earnings of individual $i$ in group $l$ when she is an entrepreneur as $y_{1}\left(X_{l}, i\right)=p_{1} \theta\left(X_{l}\right) s_{1}(i)$, and when she is a worker as $y_{0}(i)=p_{0} s_{0}(i)$. Defining the ratios $s \equiv \frac{s_{1}}{s_{0}}, p \equiv \frac{p_{0}}{p_{1}}$, and $q \equiv p \frac{y_{1}}{y_{0}}$, the earnings-maximizing occupational choice of individual $i$ is to consider becoming an entrepreneur if:

$$
q\left(X_{l}, i\right) \geq p
$$

and to consider being a worker if $q\left(X_{l}, i\right) \leq p$. Here the term $q\left(X_{l}, i\right)=\theta\left(X_{l}\right) s(i)$ summarizes the individual's comparative advantage in entrepreneurship, at parity prices, as a function of social interaction and skills.

When individuals have different skills, the character of the price equilibrium depends crucially on the marginal entrepreneur and how his comparative advantage changes as more and more untalented people become entrepreneurs. If the benefits of interaction are weak and the marginal entrepreneur "deteriorates" as the more intrinsically untalented people enter the business, then the economy reduces to a standard Roy model, or sorting model, with a unique unspecialized equilibrium. Only if the interaction effect is strong enough to overcome skill heterogeneity can interaction change the character of the equilibrium.

\section{$\{$ Insert Figure 5\}}

Without loss of generality, order individuals from the greatest to the smallest comparative advantage in entrepreneurship, so that the skill ratio is decreasing in

\footnotetext{
${ }^{14}$ These draws can be partially correlated within groups with the assumption that the correlation is the same for every group.
} 
$i, s^{\prime}(i) \leq 0$. The marginal entrepreneur is then the individual indexed by $i=X_{l}$, and her comparative advantage is $q\left(X_{l}, X_{l}\right)$. To prevent the economy from reducing to a sorting model, assume that the interaction effect trumps heterogeneity:

Assumption 3 Interaction dominates at the margin: $\frac{d}{d X_{l}} q\left(X_{l}, X_{l}\right)>0$.

This assumption implies that the solid line in Figure 5 is upward sloping. The equilibrium distribution $\left(X_{A}, X_{B}\right)$ must be competitively supplied and enough goods and services must be produced to meet demand. Using a similar line of reasoning as in the previous section, based on $V$ being strictly increasing in both arguments, it follows from Assumption 3 that there are three equilibria: one unstratified, denoted $\left(X_{A}^{U}, X_{B}^{U}\right)$; one where minority $A$ specializes, denoted $\left(X_{A}^{A}, X_{B}^{A}\right)$; and one where majority $B$ specializes, denoted $\left(X_{A}^{B}, X_{B}^{B}\right) \cdot{ }^{15}$

In the equilibrium where minority $A$ specializes as entrepreneurs, the mean earnings of $A \mathrm{~s}$ are higher than the mean earnings of $B \mathrm{~s}$, and vice versa in the equilibrium where group $B$ specializes. To see why, let $y=\max \left(y_{0}, y_{1}\right)$ be actual individual earnings, and denote mean group earnings as $\mu=\int_{0}^{1} y d i$.

Proposition 4 Earnings covary with entrepreneurship: $\mu\left(X_{l}\right)>\mu\left(X_{l^{\prime}}\right)$ if $X_{l}>X_{l^{\prime}}$.

Proof: Since people sort into occupations, mean earnings can be rewritten as

$$
\mu\left(X_{l}\right)=\int_{0}^{1} y_{0}(i) d i+\int_{0}^{X_{l}}\left(y_{1}\left(X_{l}, i\right)-y_{0}(i)\right) d i
$$

Rearranging, the difference in mean earnings between the two groups is:

$$
\mu\left(X_{l}\right)-\mu\left(X_{l^{\prime}}\right)=\int_{0}^{X_{l^{\prime}}}\left(y_{1}\left(X_{l}, i\right)-y_{1}\left(X_{l^{\prime}}, i\right)\right) d i+\int_{X_{l^{\prime}}}^{X_{l}}\left(y_{1}\left(X_{l}, i\right)-y_{0}(i)\right) d i
$$

where both parts of the expression are positive. The first part is strictly positive due to the interaction effect, $\frac{\partial y_{1}\left(X_{l}, i\right)}{\partial X_{l}}>0$, and the second part is positive because of sorting, $y_{1}\left(X_{l}, i\right) \geq y_{0}(i)$ for all $i \leq X_{l}$.

This unequivocal effect on mean earnings at the group level does not carry through to the sectoral level. Depending on the joint distribution of skills, mean earnings in either sector can increase or decrease as interaction increases entrepreneurial productivity and shifts people of different ability between sectors. The effect of interaction on sectoral earnings is similar to the effect of changing skill prices, which cannot be signed for a general skill distribution (Heckman and Honore, 1990).

\footnotetext{
${ }^{15}$ Note that Assumptions 2 and 3, when combined, put both an upper and a lower bound on the interaction effect: $-\frac{d \ln s}{d X_{l}}<\frac{d \ln \theta}{d X_{l}}<\frac{1}{X_{l}}$.
} 
The difference in mean earnings, normalized in units of goods, is shown in Figure 6 below for the equilibrium with minority specialization. The exact derivation is included in the appendix. The relative price of goods to services is always such that the marginal entrepreneur is indifferent between sectors. Keeping track of whether the marginal entrepreneur is in group $A$ or in group $B$ depending on the occupational distribution, the equilibrium price can be expressed as:

$$
p= \begin{cases}q\left(X_{l}, X_{l}\right) & \text { if } X_{l}>X_{l^{\prime}} \text { and } X_{l^{\prime}}=0, \text { or } X_{l}<X_{l^{\prime}} \text { and } X_{l}>0 \\ q\left(X_{l^{\prime}}, X_{l^{\prime}}\right) & \text { if } X_{l}>X_{l^{\prime}} \text { and } X_{l^{\prime}}>0, \text { or } X_{l}<X_{l^{\prime}} \text { and } X_{l}=0\end{cases}
$$

When increasing the size of the entrepreneurial sector in the equilibrium with minority specialization, the relative price of goods to services increases continuously as the marginal entrepreneur in group $A$ becomes more and more productive. This increase in price continues until all $A$ s are entrepreneurs.

\section{$\{$ Insert Figure 6\}}

To expand the entrepreneurial sector further from the point where everyone in group $A$ are entrepreneurs, the price has to drop discretely from $p=q(1,1)$ to $q(0,0)$, to lure the unproductive $B$ s into the entrepreneurial sector as well. The earnings differential between groups $A$ and $B$ moves accordingly, as shown in Figure 6, increasing continuously until all $A$ s are entrepreneurs, at which point earnings jump in response to the discontinuous drop in the relative price.

\section{Relationships in a Social Network}

Since interactions have been restricted to be random, the analysis has so far abstracted from changes in the social structure that could arise in response to the productive value of interaction. The most interesting question is whether the majority will split up into smaller social groups, formed around occupation, to capitalize on interaction. If such splinter groups could form costlessly, then social interaction would no longer be able to generate occupational stratification along ethnic lines.

By developing a utility-based theory of interaction, explicitly stating social preferences and characterizing the optimal social structure, this section shows that splinter groups will not arise so long as preferences are sufficiently diverse, and so long as different social relationships are not close substitutes for one another. Under these two premises it is costly to confine social interactions to within a small group since the quality of social matches deteriorates with decreasing group size.

The theory developed in this section is constructed around a standard marriage market as in Becker (1973). In addition to spousal matching, people are also related by birth, which yields a larger social structure where individuals are interrelated not 
just pairwise but in a social network. Since the social network is derived as the outcome of matching, the problem analyzed here is different in nature from the problems most commonly analyzed in the social network literature, for example in Jackson and Wolinsky (1996), which focuses on strategic interaction between identical agents.

\subsection{The Marriage Market}

Take a very large finite population $i=1, \ldots, N$, which is divided into mutually exclusive and exhaustive families by birth, with each family consisting of $d>3$ individuals. Every person $i$ independently draws a trait $t_{i}$, which could be for example beauty or intelligence, uniformly distributed between zero and one:

Assumption 4 Individual traits $t_{i}$ are independent draws.

The independence of the draw signifies what can be thought of as maximal diversity: even within families people have different traits.

Based on realized traits, each person is assigned a spouse. To simplify, there are no gender restrictions and spouses can belong to the same family. ${ }^{16}$ Traits are assumed to be complementary inputs in marriage. A marriage between $i$ and $j$ yields utility $u\left(t_{i}, t_{j}\right)$, where the function $u$ is symmetric and strictly increasing with a positive cross-derivative:

Assumption 5 Inputs are complementary: $u\left(t_{i}, t_{j}\right)=u\left(t_{j}, t_{i}\right), u_{1}>0, u_{2}>0$ and $u_{1,2}>0$.

Since different relationships produce different utility, social relationships are not perfect substitutes and there is an optimal matching of spouses. Assume that utility is transferable, in which case the efficient spousal matching has to maximize aggregate utility. Labelling individuals according to rank, so that $t_{1}<t_{2}<\ldots,{ }^{17}$ it follows that the efficient matching is positively assortative: person one marries person two, person three marries person four, ..., and person $N-1$ marries person $N$. See the appendix for proof.

\subsection{Splinter Groups}

Say that two people $i$ and $j$ are related if they are married and/or belong to the same family. Define a splinter group as a proper subset of the population where no one in the subset is related to anyone outside of that subset. Given an efficient assignment of

\footnotetext{
${ }^{16}$ Removing gender restrictions maps this problem into a one-sided assortative matching problem. One-sided assortative matching is used in a different context in Kremer (1993).

${ }^{17}$ Since having equal-valued traits, $t_{i}=t_{j}$, is of measure zero, this possibility is ignored.
} 
spouses in a very large population where traits are independently distributed, it follows that:

Proposition 5 The probability that splinter groups exist is zero.

See the appendix for proof. A partial explanation for this result is that if person $i$

marries person $j$, then because of the independence of traits, it is unlikely that anyone else in $i$ 's family marries into $j$ 's family as well. As the population grows larger, it becomes less and less likely that there is more than one marriage between the families of $i$ and $j$. This "mismatch" prevents $i$ and $j$, and their families, from socially isolating themselves from the larger population.

The problem is more interesting than what this partial intuition conveys, however. The likelihood of more than one marriage between two particular families decreases as the population grows larger, but on the other hand, the number of families for whom this event could occur increases. If, for example, $d$ had been equal to two, then these two effects would have balanced, so that small splinter groups would have formed even as the population approached infinity. In addition to the proof in the appendix of why no splinter groups occur when $d$ is greater than three, the appendix also presents a more structured intuition for the result, using a branching tree to trace out relationships in the population.

\subsection{Implications for Productivity}

The social network developed here allows more individual choice than the random interaction model analyzed earlier, since here occupational choice can be made contingent on every aspect of the social structure. The main results from the random interaction model continue to hold nevertheless. A large group cannot align social relationships so as to maximize productivity in a small sector where social interaction and productivity are complementary, without incurring the cost of deteriorating social matches that comes from breaking up into smaller groups. This follows from the result that no splinter groups arise under first-best matching on social traits. Since the social choice set of ethnic minority groups is restricted anyway, these groups can limit their social interactions to a single sector at no alternative cost. Ethnic minorities are therefore well suited for social interaction-intensive occupations.

A social network with the same properties could also be derived from a meeting technology where spouses meet and marry at random. The social structure derived here can therefore equally well be thought of as arising in a rigid environment where people meet randomly, as arising from efficient matching. Since randomness is likely to play a role in who marries whom, this adds additional strength to the result. Breaking up into smaller groups does not only carry a social utility cost, but also carries the cost of bypassing random marriages. 


\section{Analysis of US Entrepreneurial Stratification}

This section assesses the extent to which the social isolation and small group sizes of ethnic immigrant communities lead to entrepreneurial stratification. We begin with a description of our US 2000 Census of Populations sample and our metrics for calculating entrepreneurial clustering and social isolation. Our initial analysis includes descriptive measures of prominent ethnic entrepreneurship groups and OLS regressions of our ethnic concentration ratios on ethnic group size and isolation. We then address endogeneity concerns using a two-stage least squares instrumental variable (IV) approach. We corroborate evidence through a series of robustness checks, including a simulation methodology that verifies our entrepreneurial cluster measures are robust to controls for small ethnic group sizes. We close with a discussion of earnings.

\subsection{US Census of Populations Data}

We collect data from the 2000 Census of Populations using the Integrated Public Use Microdata Series (IPUMS). Our core empirical work focuses on the $5 \%$ state-level sample, and we use person weights to create population-level estimates. The depth of the $5 \%$ sample is important for generating sufficient samples in our detailed ethnicityindustry bins for entrepreneurs and wage workers. We also use the $19805 \%$ sample to construct one set of instruments, and a second set of instruments uses 1991 information on the United Kingdom obtained from IPUMS-International.

We define ethnic groups using detailed birthplace locations and to a lesser extent detailed language measures. Birthplace locations form the primary groups, and we merge related birthplace locations into the same ethnicity. For example, we collapse Scotland, Wales, and non-specific United Kingdom designations into England. We generally favor connecting groups that have undergone major geopolitical break-ups to their current designations, but this is not always possible in some difficult cases like the Balkan states and states of the former Soviet Union. We also utilize the language variable to create sub-groups among some larger birthplaces, for example separating Gujarati and Punjabi Indian. In the end, our preparation develops 146 potential ethnic groups from 198 birthplace locations. As further described below, most of our empirical work focuses on 77 larger ethnic groups that have at least one industry where we observe ten or more IPUMS observations (equivalent to about 200 workers in the industry nationally depending upon sample weights).

We assign industry classification and self-employment status through the industry and class-of-work variables. IPUMS uses a three-digit industry classification to categorize work setting and economic sector of employment. Industry is distinct from a worker's technical function or "occupation," and workers in multiple industries are assigned to the industry of greatest income or amount of time spent. We utilize the 
1990 IPUMS industry delineations for temporal consistency. The class-of-work variable identifies self-employed and wage workers, and we exclude unemployed workers, those out of the workforce, and those with unknown work status. We define a "cluster" as an \{industry, class of work\} pairing. For example, a self-employed hotelier is classified differently than a wage earner in the hotel and motels industry. Our empirical analysis focuses on self-employment industries, and we consider total industry employment in robustness checks. We drop observations of 24 industries in which self-employment is non-existent (e.g., military, railroads, the US postal service, religious organizations). Our final sample includes 200 industries.

We narrow our sample using demographic information available in the IPUMS dataset. For immigrants and US-born workers, we retain males between 30 and 65 years old who are living in metropolitan statistical areas. We further require that immigrants arrived in the United States before 1990 to avoid issues related to migration for temporary employment (which in the United States is typically in roles selected by the sponsoring firm and can last for six years on the H-1B program). To circumvent schooling decisions that are influenced by other forms of social interaction than those discussed here, we require that immigrants be at least 20 years of age at the time of immigration to the United States. Immigrants must also have immigrated no earlier than 1969. ${ }^{18}$ Our final sample contains 1,604,350 observations representing 34,984,436 people when applying sample weights. Of these individuals, 143,327 observations, representing 3,141,080 people, are immigrants.

\subsection{Clustering in Entrepreneurial Activities}

We study entrepreneurship through self-employment status. The use of the term "entrepreneurship" differs greatly across studies, and our focus here is on a broad definition that includes both employer firms and sole proprietors. Likewise, our definition captures firms with a full range of growth ambitions and prospects, from independent artisans to high-growth firms supported by venture capital investors. As we consider population-level counts, our definitions are mostly determined through "Main Street" activity like restaurants, barber shops, construction, retail trade, and similar. Because classification is discrete in the class-of-work variable, we tend to only capture self-employment when it is the main activity of an individual (e.g., not capturing academics who consult part-time to companies).

The central focus of our theory is on the concentration of ethnic entrepreneurs in particular industries. We devise "overage" ratios, defined below, to quantify the

\footnotetext{
${ }^{18}$ The Immigration and Naturalization Services Act of 1965 abolished national origin restrictions, allowing large-scale non-European immigration for the first time since the Chinese Exclusion Act of 1882. Our sample requires immigration no earlier than 1969 since the Act went into effect in June of 1968.
} 
heightened rate of ethnic self-employment in a particular industry and also across a range of industries. Our core metrics, used in most of our empirical analysis and the default for the discussion below, only retain individuals that are self-employed, considering variation in ethnic groups across industries. In robustness checks we also calculate overage ratios on industry total employment, combining wage earners and self-employed workers. ${ }^{19}$

To define our metrics, we identify each employed worker $x_{i}$ 's ethnic group and industry. We define $O V E R_{l k}$ as the ratio of an ethnic group l's concentration in an industry $k$ to the industry's national employment share. Thus, if ethnic group $l$ has $N_{l}$ total workers and $N_{l}^{k}$ workers in industry $k$, then $X_{l}^{k}=N_{l}^{k} / N_{l}$ and $O V E R_{l k}=$ $X_{l}^{k} / X^{k}$. The subscript $l k$ denotes that these two metrics are unique to each groupindustry pairing, and we calculate $O V E R_{l k}$ for each industry where the ethnic group is employed.

To move from these industry-level values to analyses of entrepreneurial group concentration, our core estimates take a weighted average across industry-level overage values for each ethnic group, with the weights being the share of the group's selfemployment that is present in that industry:

$$
O V E R 1_{l}=\sum_{k=1}^{K} O V E R_{l k} X_{l}^{k}
$$

Our estimations ultimately use the log value of this $O V E R 1$ metric. We also consider several variants in robustness checks. One set of robustness checks considers different samples for $O V E R 1_{l}$, such as including rural populations or excluding natives from the $X^{k}$ denominators used in $O V E R_{l k}$. A second approach varies the formula in several ways:

1. Weighted average over the three largest industries for ethnic group $l: O V E R 2_{l}=$ $\sum_{k^{\prime}=1}^{3} O V E R_{l k^{\prime}} X_{l}^{k^{\prime}} / \sum_{k^{\prime}=1}^{3} X_{l}^{k^{\prime}}$, where $k^{\prime}=k$ such that $\sum_{k^{\prime}=1}^{3} N_{l}^{k^{\prime}}$ is maximized.

2. Weighted average over the three largest industry-level overages for ethnic group $l$ : $O V E R 3_{l}=\sum_{k^{\prime}=1}^{3} O V E R_{l k^{\prime}} X_{l}^{k^{\prime}} / \sum_{k^{\prime}=1}^{3} X_{l}^{k^{\prime}}$, where $k^{\prime}=k$ such that $\sum_{k^{\prime}=1}^{3} O V E R_{l k^{\prime}}$ is maximized.

3. Maximum overage: $O V E R 4_{l}=\max _{l}\left[O V E R_{l k}\right]$.

\footnotetext{
${ }^{19}$ It may seem appealing to use wage earners instead as a counterfactual to self-employed workers. This approach, however, does not offer a good counterfactual as ethnic entrepreneurs show a greater tendency to hire members of their own ethnic groups into their firms (e.g., Andersson et al., 2009, 2012; Åslund et al., 2012; Kerr et al., 2015). A Yemeni grocery store owner, taking as an example our second most concentrated cluster discussed below in Table 1b, is far more likely to hire Yemeni employees into the growing firm. We thus use this as a robustness check that provides us deeper sample sizes.
} 
In making these calculations that measure extreme values, we need to be careful about small sample size. We first require that ethnicities included in our sample have at least one industry where we possess ten or more IPUMS observations. Our concern is that spurious clusters could appear in small ethnic groups and obscure industries due to very small sample size or small population size. As an example of a spurious cluster, consider an immigrant group with only two observations. By default this group will be extremely overrepresented in at least one industry, since half or more of its population must be working in a single industry. By focusing on settings where we observe at least ten observations (equivalent to around 200 workers), we reduce the scope for these biases.

After completing all of these data preparation steps, we have 77 ethnic groups through which we can study entrepreneurial concentration hypotheses. $O V E R 1_{l}$ then takes the weighted sum across industries, while $O V E R 2_{l}$ considers the three largest industries for an ethnic group. In most cases, $O V E R 2_{l}$ is bigger than $O V E R 1_{l}$ as concentration is often linked to substantial numerical representation; other cases exist however where the three largest industries for an ethnic group have lower concentration than the group as a whole due to the fact that they are focused on big industries. We calculate our metrics of extreme values, captured in $O V E R 3_{l}$ and $O V E R 4_{l}$, over ethnic group-industry clusters where we have at least ten observations.

Table 1a provides our largest overage ratios ordered by $O V E R 1_{l}$. We find evidence of strong entrepreneurial clustering. For example, Gujarati Indians have an average overage ratio of 33 across the industries of their self-employment work, and an average overage ratio of 59 in their three largest industries. Their max overage is in the hotel and motel industry, which we further explore in Table 1b. Yemeni immigrants display the overall highest industrial concentration for entrepreneurship, with particular emphasis on grocery stores. The last three columns of Table 1a provide broader statistics about each ethnic group, such as its total employment (entrepreneurial and wage workers), self-employment share, and in-marriage rates. ${ }^{20}$

Table $1 \mathrm{~b}$ displays the maximum overages observed at the industry level for ethnic groups, ordered by max self-employment overage. The table displays for the ethnic groups their industry of max self-employment overage, the industry of max overage when using all workers, and the industry where the most workers for the ethnic group are occupied in terms of absolute counts. In 17 of 25 cases shown, the industry where the ethnic group displays the highest concentration for self-employment is the same as the industry where the ethnic group shows the highest concentration for total employ-

\footnotetext{
${ }^{20}$ Appendix Tables 1a and 1b report pairwise correlations and pairwise rank correlations for eight variants in overage ratios. All correlations exceed 0.4 and are statistically significant at a $5 \%$ level. The greater tendency to entrepreneurship among immigrants evident in Table 1a has been previously observed and discussed by Fairlee (2008), Hunt (2011), and Kerr and Kerr (2015). Kerr (2013) and Fairlie and Lofstrom (2013) provide reviews.
} 
ment. In 8 of 25 cases, the industry of maximum concentration is also the industry where the ethnic group employs the most workers in an absolute sense. The industry size variable ranks industries from largest (1) to smallest (200) in terms of their overall size in the economy. Most of the maximum-concentration industries in the first two industry lists are of moderate size; industries in the third set for highest absolute count of ethnic employees tend to be larger industries.

We pause now to reflect on some of the features displayed in these tables. First, it is noteworthy from viewing the tabulations that some important factors outside of the model are surely aiding group concentration but are not captured by our theoretical and empirical work, while still being of a similar spirit in terms of the conceptual ideas of this paper. For example, we treat the taxi industry as a single industry for our empirical work, but in most respects taxi markets are segmented by cities. Frequent travelers note the degree to which different ethnic groups appear to dominate the taxi industry on a city-by-city basis, with the most important group for each city being different. In fact, more broadly, many industries of maximum concentration (e.g., grocery stores, gas stations) are cases where geography can play an important role. This suggests we are likely under-estimating true concentration in this regard. ${ }^{21}$ A second, but seemingly smaller, factor from these tables is that taste variations in services offered could make for separate markets (e.g., restaurants). These taste-based factors clearly exist and explain entrepreneurial clustering, but we find it more exciting and important to observe entrepreneurial clustering without resorting to taste-based elements (e.g., it is unclear if Greek and Italian restaurants are really separate markets).

On a related note, social interaction effects should in principle be relevant to any setting where the complementarity between social interaction and skill acquisition is strong. However, occupations and industries that require specific education and skills that are typically acquired early in life are not amenable to the forces that we model in which immigrants arrive in the United States as adults. Thus, adult immigrants find it harder to enter the medical profession, despite its significant interplay between social and professional interactions, given medicine's deep professional requirements and extensive training period. Many of the displayed entrepreneurial activities that are subject to ethnic concentration have much shorter training cycles and fewer degree or occupational licensing requirements.

\subsection{Ethnic Isolation and In-Marriage Rates}

Our theory emphasizes how entrepreneurial knowledge can be supported and diffused in tightly knit ethnic communities, and we predict that more-isolated and smaller communities are more likely to display entrepreneurial clustering within a particular

\footnotetext{
${ }^{21}$ Unfortunately, the data counts become very thin for segmenting by geography using IPUMS. Future work using universal linked employer-employee data can analyze these features.
} 
industry. Our proxy for these social interactions is developed through within-group marriage rates among ethnicities, which can be an effective metric if sorting in the marriage market is similar to sorting in other social relationships. Representative work on this topic includes Kennedy (1944), Bisin and Verdier (2000), and Bisin et al. (2004). High marriage rates within an ethnic group, also termed in-marriage or endogamy, suggest greater social isolation and stratification. Mandorff (2007) shows with the General Social Survey the predictive power of in-marriage rates for friendship structures within ethnic groups. Conversely, groups with less in-marriage are more socially integrated into the larger population. We use in-marriage rates to test our hypothesis that socially stratified ethnicities display greater entrepreneurial activity.

We calculate in-marriage rates for ethnicities using a second dataset developed from IPUMS. We focus on women and men immigrating to the United States between the ages of 5 and 15 and who are between ages 30 and 65 in 2000. The age at immigration restriction prevents the inclusion of children coming to the United States for adoption since most of these children are adopted before the age of five. Setting the upper limit at 15 years of age prevents the inclusion of immigrants already married or immigrating to the United States for marriage. We exclude individuals already married at the time of immigration to the United States since their behavior does not model well levels of social isolation in the United States. Due to these features, this sample is mutually exclusive from that used to calculate our overage metrics. ${ }^{22,23}$

Most immigrant groups are socially segregated with respect to marriage, some very strongly so. With random matching for marriage and equal male and female migration, in-marriage rates would roughly equal a group's fraction of the overall population. The in-marriage rates shown in Table 1a are much higher, with all but three cases exceeding $50 \%$. The table further shows the high entrepreneurship concentration of these groups as well, with pairwise correlations of 0.51 and 0.60 for in-marriage rates and the $O V E R 1_{l}$ and $O V E R 2_{l}$ metrics, respectively, among the groups listed in Table 1a.

\footnotetext{
${ }^{22}$ IPUMS identifies spouses when both are listed as being in the same household. We do not require the spouse to also be an "eligible" immigrant. For the marriage to count as an in-marriage, the spouse must share the same birthplace location or ancestry as the eligible individual in the sample.

${ }^{23}$ We use the same methodology to determine in-marriage rates with the 1980 US Census of Populations and the 1991 UK Census of Populations, and these metrics later serve as instruments for the 2000 US in-marriage rate. We use a rate calculated at a regional level in cases where we have insufficient data for an ethnic group. The regions are defined for birthplace locations along the same lines as the IPUMS delineations. The IPUMS codebook defines the following regions: Africa, Americas, Asia, Central America/Caribbean, Central/Eastern Europe, East Asia, Europe, India/Southwest Asia, Middle East/Asia Minor, Northern Europe, Oceania, Other North America, Russian Empire/Baltic States, South America, Southeast Asia, Southern Europe, US Outlying Area, and Western Europe.
} 


\subsection{OLS Empirical Tests}

Our empirical estimations focus on the core prediction that smaller and more-socially isolated ethnic groups should display greater industrial concentration towards entrepreneurship. To establish this, we use the following regression approach:

$$
O V E R 1_{l}=\alpha+\beta_{1} S I Z E_{l}+\beta_{2} I S O L_{l}+\varepsilon_{l},
$$

where $S I Z E_{l}$ is the negative of the log value of group size and $I S O L_{l}$ is the log in-marriage rate of the group. We take the negative of size so that our theoretical prediction is that $\beta_{1}$ and $\beta_{2}$ are positive. We report all coefficients in unit standard deviation terms for ease of interpretation with our overage metrics. Our baseline regressions winsorize variables at their $10 \%$ and $90 \%$ levels to guard against outliers, weight estimations by log ethnic employment for each group, and report robust standard errors. Robustness checks below consider adjustments to all of these specification choices.

The first column of Table 2 shows a very strong relationship of group size and social isolation to the three overage measures. A one standard-deviation decrease in group size is correlated with a 0.63 increase in average entrepreneurial concentration across all industries. Similarly, a one standard-deviation increase in the in-marriage rate translates into a 0.52 standard-deviation increase in overage.

Columns 2-5 contain several robustness checks. Columns 2 and 3 show very similar results when we drop our sample weights and winsorization steps, respectively. Column 4 takes a more aggressive strategy of introducing fixed effects for each origin continent. Doing so reduces both coefficients modestly, yet they remain overall quite strong. Columns 5 and 6 show similar results when using a median regression format or when bootstrapping standard errors. These last two columns should be compared to Column 2 given their unweighted nature.

Columns 7 and 8 introduce additional controls to consider whether smaller sample sizes for ethnic groups create concentration ratios mechanically. Our metric design attempts to guard against this, yet we can also conduct Monte Carlo simulations to test. In these simulations, we randomly assign individuals to industries and self-employment status. In one version, used for Column 7 , we draw industry and self-employment status independently from each other, which means that we tend to predict the same self-employment rates across industries. In a second version used in Column 8, we jointly draw the two components such that we mimic the industry-by-industry entrepreneurship rates observed in the data. From these 1000 Monte Carlo simulations, we calculate for each ethnic group the average observed overage. Introducing these controls does not impact our estimations except that the size relationship diminishes modestly.

Table 3 next reports robustness checks on our metric design. The first column 
repeats our baseline estimation. Column 2 shows that a focus on the three largest industries for an ethnic group (i.e., $O V E R 2_{l}$ discussed above) increases the relative importance of social isolation for predicting overages. Column 3 uses the full worker sample, Column 4 calculates overages only relative to immigrant populations by excluding natives from the denominator shares, and Column 5 adds rural workers into the self-employment overage calculations. The results are very robust to these adjustments. Columns 6 and 7 examine extreme values using the $O V E R 3_{l}$ and $O V E R 4_{l}$ metrics defined above. These extreme values show a weaker connection to group size, placing even more prominence on group isolation.

Table 4 further tests the effects of relative size and isolation on entrepreneurial clustering by using non-parametric regressions. We partition our size and isolation variables into terciles and create indicator variables for each combination of \{smallest size, medium, largest size and \{most isolated, medium, least isolated\}. We assign ethnic groups that fall into [largest size, least isolated] as the reference category, and coefficients on the indicator variables for other categories are measured relative to this group. The results continue to support the theory. The top row of Table 4 quantifies that the [smallest size, most isolated] groups have entrepreneurial concentrations that are 2.5 standard deviations greater than the [largest size, least isolated] groups.

Equally important, the pattern of coefficients across the other indicator variables suggests that the effects estimated in Table 2 are quite regular and not due to a few outliers having an outsized impact. For example, holding the ethnic group size constant by considering each set of three rows in Table 4, higher levels of social isolation strongly and significantly correspond to larger overages. Flipping it around, holding social isolation constant, smaller group sizes also promote greater concentration within each isolation category, with the exception of the least socially isolated tercile.

In addition to these, we have conducted other robustness exercises. Perhaps most important, unreported analyses assess whether our focus on self-employment gives skewed results compared to the isolation of employer firms. We consider a modified form of our overage measures that uses information contained in the Survey of Business Owners (SBO) to adjust our metrics for industry-level propensities for being an employer firm vis-à-vis sole proprietors. This can only be done under the very strong assumption that ethnic groups have equal proclivity to become employer firms versus otherwise. This approach yields very similar results to those reported, but we remain cautious that this does not fully answer these questions. Ultimately, an important topic for future research is to use employer-employee data that contain the ethnic origins of founders and employees to better understand these relationships. 


\subsection{Empirical Tests: 1980 Values}

We next consider IV specifications to test against reverse causality concerns (e.g., that isolated business ownerships lead to greater social isolation or lower group sizes). We use two sets of instruments. The first set of instruments builds upon an idea developed in our model, that initial conditions can have lasting and persistent impacts, which is also shown quite strongly in this context by the empirical work of Patel and Vella (2013). We thus use the lagged 1980 values of ethnic group size and in-marriage rates in the United States to instrument for 2000 levels. The distinct advantage of these instruments is that they can be calculated from the 1980 Census of Populations in a manner very comparable to our endogenous regressors. Despite this comparable data structure and collection procedure, the ethnic divisions in 1980 are less detailed than in 2000 and thus, in some cases, the same 1980 value must be applied to several 2000 ethnic groups. We thus cluster standard errors around the 43 groups present in the 1980 data, with other aspects of the IV estimations being the same as OLS specifications.

The first-stage results with this instrument set are quite strong. The first two columns of Table 5 show that these instruments have very strong individual predictive power and a combined joint F-statistic of $24 .^{24}$ The exclusion restriction requires that the 1980 group sizes and in-marriage levels only impact 2000 entrepreneurship to the extent that they shape current group size and social isolation, which seems reasonable. One possible counter to this, on the other hand, is that some of the 1980 respondents are still employed in 2000, and this may carry with it persistence that violates the exclusion restriction.

The second-stage results in Column 3 are quite similar to the OLS findings. The IV specifications suggest that a one standard-deviation decrease in ethnic group size increases overage by 0.76 standard deviations. A one standard-deviation increase in isolation leads to a 0.52 standard-deviation increase in entrepreneurial concentration. These results are well-measured and economically important. The size coefficient grows modestly from its OLS baseline, while the in-marriage rate coefficient declines slightly. The results are precisely enough estimated that we can reject at a $5 \%$ level the null hypothesis in $\mathrm{Wu}-\mathrm{Hausman}$ tests that the instrumented regressors are exogenous. These IV results strengthen the predictions of our theory that smaller, more isolated groups are more conducive to entrepreneurial clustering.

\subsection{Empirical Tests: Gravity Model and UK Values}

Our second IV approach uses as instruments the predicted ethnic group size from a gravity model and in-marriage rates from the United Kingdom in 1991. This is an

\footnotetext{
${ }^{24}$ The F-statistic comes from the Kleibergen-Paap Wald rank F-statistic used when standard errors are clustered or robust and is based off the Cragg-Donald F-test for weak instrumentation.
} 
even stronger test of the model, with advantages and liabilities compared to our 1980 instruments. First, to instrument for ethnic group size, we use a gravity model to quantify predicted ethnic size based upon worldwide migration rates to the United States. The original application of gravity models was to trade flows, where studies showed that countries closer to each other and with larger size tended to show greater trade flows, similar to the forces of planetary pull. This concept has also been applied to the migration literature, and we similarly model

$$
S I Z E_{l}=\alpha+\beta_{1} D I S T_{l}+\beta_{2} P O P_{l}+\varepsilon_{l},
$$

where $D I S T_{l}$ is the log distance to the United States from the origin country and $P O P_{l}$ is the log population of the origin country. For this purpose, we estimate log ethnic group size in the United States as the dependent variable (without a negative value being taken as in earlier estimations). Unsurprisingly, lower distance $\left(\beta_{1}=-1.56\right.$ $($ s.e. $=0.22))$ and greater population $\left(\beta_{2}=0.38(\right.$ s.e. $\left.=0.06)\right)$ are strong predictors of ethnic group size in the United States. We take the predicted values from this regression for each ethnic group as our first instrument.

For our second instrument of in-marriage rates in the United States, we calculate the in-marriage rates in the 1991 UK Census of Populations. This approach is attractive as the social isolation evident in the United Kingdom a decade before our study is only likely to be predictive of US self-employment rates to the extent that the British isolation captures a persistent trait of the ethnic group. The limitation of this instrument is that we are only able to calculate this for 24 broader ethnic sets than our base observations. We map our observations to these groups and cluster the standard errors at the UK group level.

Columns 4-5 of Table 5 again report the first-stage relationships. The instruments remain individually predictive of their corresponding endogenous regressor, and they have a joint F-statistic of 35.5. Similar to the 1980 US instruments, the minimum 2SLS relative bias that can be specified is less than 10\%. This implies that we can specify a very small bias and still reject the null hypothesis that the instruments are weak. The bias level is determined by the minimum eigenvalue statistic and Stock and Yogo's (2005) 2SLS size of the nominal 5\% Wald test.

The second-stage results are again comparable to our core OLS findings. The size results are a bit lower than OLS, while the social isolation effects are even stronger than OLS, with elasticities of around 0.67 . We now fail to reject at a $5 \%$ level that the instrumented regressors are exogenous, but we do reject it a $10 \%$ level.

Table 6 shows a set of robustness checks with the two IV approaches. The results are quite similar with the simple adjustments of excluding sample weights, dropping winsorization, or using bootstrapped standard errors. We drop the robustness checks of median regressions and continent fixed effects, with the latter being due to our direct use of distance for predicted ethnic group size. 
The results with simulated overage controls are more interesting and deserve greater comment. It becomes harder in the presence of the simulated overage controls for us to establish a high-quality first stage for the size variable. This is workable enough in the case of the 1980 size instrument, but it is not feasible for the predicted size relationship in the gravity model. Intuitively, both the instrument and predicted overage are being built upon the same data, making it hard to separate them.

Accordingly, in Columns 5 and 6, we start by just instrumenting for the isolation metric, entering size and the predicted overage as control variables. These results are quite strong and comparable to the base IV. In Columns 7 and 8, we conduct the double IV for the 1980 instruments, which maintain a first-stage relationship, and find qualitatively similar results.

Table 7 shows comparable patterns with the alternative metric designs. The results for social isolation are robust in all specifications. Those for size are mostly robust, with a few exceptions in Panel B with the predicted size instruments. Table 8 also shows very similar results to those reported above when expanding the gravity equation to have a squared distance term or an indicator for Canada and Mexico as bordering countries or when using underlying components of the gravity equation as direct instruments.

In summary, and looking across the OLS and IV variants, the model developed in this paper finds consistent support. The strongest findings are those for social isolation, which is a very strong predictor of entrepreneurial concentration. The weight of the evidence also supports that smaller group sizes promote entrepreneurial concentration.

\subsection{Earnings Estimations}

Our model makes an additional prediction that members of an ethnic group can achieve greater earnings when entering a common entrepreneurial occupation. In our framework, social complementarities produce a positive relationship between earnings and entrepreneurship at the group level. This prediction is in direct contrast to what would be expected if discrimination in the marketplace is the most important factor leading to segmented group occupations. The empirical work of Patel and Vella (2013) strongly shows a positive earning relationship for immigrant groups and common group occupational choices using the 1980-2000 Census of Populations data. ${ }^{25}$ To close the loop for this paper, we thus provide a brief analysis of earnings and refer readers to these complementary pieces for additional evidence.

Table 9 provides individual-level estimations of the earnings relationship. The outcome variable is the log yearly income of individuals. The core regressors, which we further describe shortly, measure the entrepreneurial activity of the individual's ethnic

\footnotetext{
${ }^{25}$ Related work also includes Chiswick (1978), Borjas (1987), Simon and Warner (1992), Rauch (2001), Mandorff (2007), Bayer et al. (2008), and Beaman (2012).
} 
group and whether the individual is self-employed. The sample is taken from the 2000 Census IPUMS. We include males aged 30-65 in 2000. Our sample contains all native males and immigrant males who migrate after 1968 (effective date of the Immigration Reform Act of 1965) and have lived in the United States for at least 10 years. Sample excludes workers whose self-employment status is unknown or not applicable, industries without self-employment, and workers living outside of metropolitan areas.

We report three core explanatory variables. The first is whether the individual is self-employed. The second is the percentage of an individual's group who are selfemployed (similar to the values reported in Table 1a), regardless of industry. Third, we measure the share of the individual's ethnic group that are employed in the industry of the focal individual. With the model developed, we anticipate both of these group measures to have positive predictive power. For natives, these latter variables are simply measured over the whole US-born population.

Our estimations also include many unreported controls for individuals that relate to earnings. We include fixed effects for PUMA geographical locations and for industries. We also control for high-school and college education, whether the individual is a native or an immigrant, whether the individual is fluent in the English language, and fixed effects for seven age categories and seven age-at-immigration categories. Regressions cluster standard errors by ethnic group and use IPUMS sample weights.

The first three columns show that all three elements are predictive of earnings. Being self-employed (a binary measure) is directly associated with a $3 \%$ increase in total earnings in the cross-section. A $1 \%$ increase in the rate of overall self-employment for an ethnic group connects to a $1 \%$ increase in total earnings. To aid interpretation, the bottom of the table also provides the standard deviation $\mathrm{x}$ beta coefficient for grouplevel variables; a one standard-deviation increase (0.0255) in group self-employment connects to $3 \%$ higher earning. Similarly, looking at ethnic group concentration for the individual in his particular industry, a $1 \%$ increase in group concentration connects to a $0.6 \%$ increase in total earnings. In standard-deviation terms, the relative effect of $5 \%$ is even larger than the $3 \%$ for group self-employment. Columns 4-6 show similar outcomes when we exclude workers in professional occupations and holders of doctorate degrees.

These results thus support the model's structure. They also signal for immigrant groups a potential positive benefit from entrepreneurial concentration. We note, however, that this analysis and the connected empirical work of Patel and Vella (2013) are just first steps toward understanding this complex and important set of relationships. We particularly believe it important for future theoretical and empirical work to consider both owners and employees of firms. Empirical work can particularly target employer-employee datasets to observe more detailed hiring and wage patterns; such work can also evaluate job transitions during the assimilation of new members of ethnic 
groups, perhaps ultimately leading to starting their own business.

\section{Conclusions}

By distinguishing between market interactions and social interactions, we have developed a theory where social relationships reduce the cost of acquiring sector-specific skills for entrepreneurship. As a result, occupational choice reinforces initial group differences, and different ethnic groups cluster in different industries. The scale economies generated by social relationships imply that social interactions, as opposed to market interactions, can result in favorable economic outcomes and self-employment conditions for minority groups. This is true when interactions are random or endogenous, with a key condition being that social relationships must not be close substitutes for one another for the broadest predictions to hold. A natural extension is to apply these theoretical concepts to the intergenerational transmission of skills and to follow occupational structure and entrepreneurial persistence across generations. This interaction mechanism can also be applied to the study of the transmission of other types of skills beyond entrepreneurship.

Taken as a whole, the Census data are consistent with social complementarities in skill acquisition operating as a stratifying force, contributing to the persistence of differences in occupational structure, entrepreneurship, and group inequality. Census data on occupational choice show that ethnic clustering is an important aspect of entrepreneurial activity. Mean earnings and entrepreneurship are positively related at the group level when controlling for other factors. Using intermarriage data in the Census as a proxy for social interactions, we find that entrepreneurial groups socialize mostly within their own group, and that stratification appears to increase with in-marriage. These results are also consistent with the economic success and social isolation of specialized minority groups throughout history. We hope that the predictions of this theory for ethnic entrepreneurship can be evaluated in settings outside of the United States given its general nature (Fairlie et al., 2010). Further connecting this to ethnic enclaves and employer-employee data will also be powerful. 


\section{References}

[1] Aldrich, Howard and Roger Waldinger. 1990. Ethnicity and entrepreneurship. Annual Review of Sociology 16: 111-135.

[2] Andersson, Fredrik, Monica Garcia-Perez, John Haltiwanger, Kristin McCue, and Seth Sanders. 2009. Workplace concentration of immigrants. Working Paper.

[3] Andersson, Fredrik, Simon Burgess, and Julia Lane. 2012. Do as the neighbors do: The impact of social networks on immigrant employment. Working Paper.

[4] Åslund, Olof, Lena Hensvik, and Oskar Skans. 2012. Seeking similarity: How immigrants and natives manage in the labor market. Working Paper.

[5] Bayer, Patrick, Stephen Ross, and Giorgio Topa. 2008. Place of work and place of residence: Informal hiring networks and labor market outcomes. Journal of Political Economy 116, 1150-1180.

[6] Beaman, Lori. 2012. Social networks and the dynamics of labor market outcomes: Evidence from refugees resettled in the US. Review of Economic Studies 79: 128-161.

[7] Becker, Gary. 1957. The Economics of Discrimination. Chicago: University of Chicago Press.

[8] Becker, Gary. 1973. A Theory of marriage: Part I. Journal of Political Economy 81: 813-846.

[9] Bertrand, Marianne, Erzo Luttmer, and Sendhil Mullainathan. 2000. Network effects and welfare cultures. Quarterly Journal of Economics 115: 1019-1055.

[10] Bisin, Alberto and Thierry Verdier. 2000. Beyond the melting pot: Cultural transmission, marriage, and the evolution of ethnic and religious traits. Quarterly Journal of Economics 115: 955-988.

[11] Bisin, Alberto, Giorgio Topa, and Thierry Verdier. 2004. Religious intermarriage and socialization in the United States. Journal of Political Economy 112: 615664 .

[12] Blalock, Hubert. 1967. Toward a Theory of Minority Group Relations. New York: John Wiley.

[13] Bonacich, Edna. 1973. A theory of middleman minorities. American Sociological Review 38: 583-594.

[14] Borjas, George. 1987. Self-selection and the earnings of immigrants. American Economic Review 80: 531-553.

[15] Borjas, George. 1992. Ethnic capital and intergenerational mobility. Quarterly Journal of Economics 107: 123-150. 
[16] Borjas, George. 1995. Ethnicity, neighborhoods and human capital externalities. American Economic Review 85: 365-390.

[17] Botticini, Marestella and Zvi Eckstein. 2005. Jewish occupational selection: Education, restrictions, or minorities? Journal of Economic History 65: 922-948.

[18] Calvo-Armengol, Antoni and Matthew Jackson. 2004. The effects of social networks on employment and inequality. American Economic Review 94: 426-454.

[19] Chiswick, Barry. 1978. The effect of Americanization on the earnings of foreignborn men. Journal of Political Economy 86: 897-921.

[20] Chung, Wilbur and Arturs Kalnins. 2006. Social capital, geography, and the survival: Gujarati immigrant entrepreneurs in the U.S. lodging industry. Management Science 52(2): 233-247.

[21] Cohen, Robin. 1997. Global Diasporas: An Introduction. London: University College London Press.

[22] Dunn, Thomas and Douglas Holtz-Eakin. 2000. Financial capital, human capital, and the transition to self-employment: Evidence from intergenerational links. Journal of Labor Economics 18: 282-305.

[23] Durlauf, Steven and Marcel Fafchamps. 2006. Social capital. In Handbook of Economic Growth, edited by Philippe Aghion and Steven Durlauf. Amsterdam: North Holland.

[24] Durlauf, Steven and Yannis Ioannides, 2010. Social interactions. Annual Review of Economics 2: 451-478.

[25] Fairlie, Robert. 2008. Estimating the Contribution of Immigrant Business Owners to the U.S. Economy. Small Business Administration, Office of Advocacy Report.

[26] Fairlie, Robert, Harry Krashinsky, and Julie Zissimopoulos. 2010. The international Asian business success story? A comparison of Chinese, Indian and other Asian businesses in the United States, Canada and United Kingdom. In International Differences in Entrepreneurship, edited by Josh Lerner and Antoinette Schoar. Chicago: University of Chicago Press.

[27] Fairlie, Robert and Magnus Lofstrom. 2013. Immigration and entrepreneurship. In The Handbook on the Economics of International Migration, edited by Barry Chiswick and Paul Miller. Amsterdam: North-Holland Publishing.

[28] Fairlie, Robert and Alicia Robb. 2007. Families, human capital, and small business: Evidence from the Characteristics of Business Owners Survey. Industrial and Labor Relations Review 60: 225-245 
[29] Glaeser, Edward, Bruce Sacerdote and José Scheinkman. 1996. Crime and social interactions. Quarterly Journal of Economics 111: 507-548.

[30] Glaeser, Edward and José Scheinkman. 2002. Non-market interaction. In Advances in Economics and Econometrics: Theory and Applications, Eight World Congress, edited by Mathias Dewatripont, Lars Peter Hansen, and Stephen Turnovsky. Cambridge, UK: Cambridge University Press.

[31] Granovetter, Mark. 1973. The strength of weak ties. American Journal of Sociology 78: 1360-1380.

[32] Greif, Avner. 1993. Contract enforceability and economic institutions in early trade: The Maghribi traders coalition. American Economic Review 83: 525548.

[33] Greif, Avner, Paul Milgrom, Barry and Weingast. 1994. Coordination, commitment and enforcement: The case of the merchant guild. Journal of Political Economy 102: 745-776.

[34] Heckman, James and Bo Honore. 1990. The empirical content of the Roy model. Econometrica 58: 1121-1149.

[35] Hunt, Jennifer. (2011). Which immigrants are most innovative and entrepreneurial? Distinctions by entry visa. Journal of Labor Economics 29(3): 417-457.

[36] Jackson, Matthew, and Asher Wolinsky. 1996. A strategic model of social and economic networks. Journal of Economic Theory 71: 44-74.

[37] Janson, Svante, Tomasz Luczak, and Andrzej Rucinski. 2000. Random Graphs. New York: John Wiley.

[38] Kennedy, Ruby. 1944. Single or triple melting-pot? Intermarriage trends in New Haven, 1870-1940. The American Journal of Sociology 49: 331-339.

[39] Kerr, Sari Pekkala and William Kerr. 2015. Immigrant entrepreneurship. Working Paper, NBER Cambridge, MA.

[40] Kerr, Sari Pekkala, William Kerr, and William Lincoln. 2015. Skilled immigration and the employment structures of U.S. firms. Journal of Labor Economics 33(S1): S147-S186.

[41] Kerr, William. 2013. U.S. high-skilled immigration, innovation, and entrepreneurship: Empirical approaches and evidence. Working Paper no. 19377, NBER, Cambridge, MA.

[42] Kihlstrom, R., and Jean-Jacques Laffont. 1979. A general equilibrium entrepreneurial theory of firm formation based on risk aversion. Journal of Political Economy 87: 719-748. 
[43] Kirzner, Israel. 1972. Competition and Entrepreneurship. Chicago: University of Chicago Press.

[44] Kirzner, Israel. 1979. Perception, Opportunity and Profit; Studies in the Theory of Entrepreneurship. Chicago: University of Chicago Press.

[45] Knight, Frank. 1921. Risk, Uncertainty, and Profit. Boston: Houghton Mifflin.

[46] Kremer, Michael. 1993. The O-ring theory of economic development. Quarterly Journal of Economics 108: 551-575.

[47] Kuznets, Simon. 1960. Economic structure and life of the Jews. In The Minority Members: History, Culture, and Religion, edited by Louis Finkelstein. Philadelphia, PA: Jewish Publication Society of America.

[48] Landa, Janet. 1981. A theory of the ethnically homogeneous middleman group: An institutional alternative to contract law. Journal of Legal Studies 10: 349-362.

[49] Lazear, Edward. 1999. Culture and language. Journal of Political Economy 107: 95-126.

[50] Lazear, Edward. 2005. Entrepreneurship. Journal of Labor Economics 23: 649680.

[51] Light, Ivan. 1977. The ethnic vice industry, 1880-1944. American Sociological Review 42: 464-479.

[52] Lucas, Robert. 1978. On the size distribution of business firms. Bell Journal of Economics 9: 508-523.

[53] Mandorff, Martin. 2007. Social networks, ethnicity, and occupation. University of Chicago Ph.D. Dissertation.

[54] Manski, Charles. 1993. Identification of endogenous social effects: The reflection problem. Review of Economic Studies 60: 531-542.

[55] Melton, Gordon, ed. 1999. Encyclopedia of American Religions. 6th ed. Detroit: Gale Research.

[56] Milgram, Stanley. 1967. The small world problem. Psychology Today 22: 61-67.

[57] Milgrom, Paul, Douglass North, and Barry Weingast. 1990. The role of institutions in the revival of trade: The medieval law merchant, private judges, and the Champagne fairs. Economics and Politics 1: 1-23.

[58] Montgomery, James. 1991. Social networks and labor-market outcomes: Toward an economic analysis. American Economic Review 81: 1408-1418.

[59] Morris, Stephen. 1956. Indians in East Africa: A study in a plural society. The British Journal of Sociology 7: 194-211. 
[60] Patel, Krishna and Francis Vella. 2013. Immigrant networks and their implications for occupational choice and wages. Review of Economics and Statistics 95(4): 1249-1277.

[61] Rauch, James. 2001. Business and social networks in international trade. Journal of Economic Literature 39: 1177-1203.

[62] Schumpeter, Joseph. 1942. Capitalism, Socialism, and Democracy. New York: Harper Brothers.

[63] Schumpeter, Joseph. 1988. Essays in Entrepreneurs, Innovations, Business Cycles, and the Evolution of Capitalism, edited by R. Clemence. Piscataway, NJ: Transaction Publishers.

[64] Simon, Curtis, and John Warner. 1992. Matchmaker, matchmaker: The effect of old boy networks on job match quality, earnings and tenure. Journal of Labor Economics 10(3): 306-330.

[65] Sowell, Thomas. 1981. Ethnic America. New York: Basic Books.

[66] Sowell, Thomas. 1996. Migrations and Cultures: A World View. New York: Basic Books.

[67] Thernstrom, Stephan, ed. 1980. Harvard Encyclopedia of American Ethnic Groups. Cambridge, MA: Harvard University Press.

[68] Winder, R. Bayly. 1962. The Lebanese in West Africa. Comparative Studies in Society and History 4: 296-333. 


\section{Appendix}

\subsection{Derivation: Earnings Differential in Figure 6}

Mean earnings denominated in terms of goods are:

$$
\frac{\mu\left(X_{l}\right)}{p_{0}}=\int_{0}^{X_{l}} p^{-1} \theta\left(X_{l}\right) s_{1}(i) d i+\int_{X_{l}}^{1} s_{0}(i) d i
$$

Replace the relative price of goods to services, $p=\frac{p_{0}}{p_{1}}$, with the comparative advantage of the marginal entrepreneur, $q$, since these two are equal in equilibrium. Denote the earnings differential as $\Delta\left(X_{l}, X_{l^{\prime}}\right) \equiv \frac{\mu\left(X_{l}\right)-\mu\left(X_{l^{\prime}}\right)}{p_{0}}$. It can be expressed as:

$$
\Delta\left(X_{l}, X_{l^{\prime}}\right)=\int_{0}^{X_{l^{\prime}}} q^{-1}\left(\theta\left(X_{l}\right)-\theta\left(X_{l^{\prime}}\right)\right) s_{1}(i) d i+\int_{X_{l^{\prime}}}^{X_{l}}\left[q^{-1} \theta\left(X_{l}\right) s_{1}(i)-s_{0}(i)\right] d i .
$$

For $X_{l}<1$ and $X_{l^{\prime}}=0$, where $q=q\left(X_{l}, X_{l}\right)$, and $q\left(X_{l}, X_{l}\right)=\theta\left(X_{l}\right) s\left(X_{l}\right)$, differentiating with respect to $X_{l}$ gives

$$
\frac{\partial \Delta\left(X_{l}, 0\right)}{\partial X_{l}}=-s^{\prime}\left(X_{l}\right) s\left(X_{l}\right)^{-2} \int_{0}^{X_{l}} s_{1}(i) d i>0 .
$$

For $X_{l}=1$ and $X_{l^{\prime}}=0$, the drop in price from $q(1,1)$ to $q(0,0)$ results in a jump in the mean earnings differential equal to

$$
\left.\Delta(1,0)\right|_{p=q(0,0)}-\left.\Delta(1,0)\right|_{p=q(1,1)}=\left(q(0,0)^{-1}-q(1,1)^{-1}\right) \theta(1) \int_{0}^{1} s_{1}(i) d i>0 .
$$

For $x=1$ and $X_{l^{\prime}}>0$, where $q=q\left(X_{l^{\prime}}, X_{l^{\prime}}\right)$, differentiating with respect to $X_{l^{\prime}}$ gives

$$
\frac{\partial \Delta\left(1, X_{l^{\prime}}\right)}{\partial X_{l^{\prime}}}=-\frac{d q}{d X_{l^{\prime}}} q^{-2} \theta(1) \int_{0}^{1} s_{1}(i) d i+s^{\prime}\left(X_{l^{\prime}}\right) s\left(X_{l^{\prime}}\right)^{-2} \int_{0}^{X_{l^{\prime}}} s_{1}(i) d i-2 s_{0}\left(X_{l^{\prime}}\right)<0 .
$$

\subsection{Proof: Stratification}

Proposition 3 Initial differences result in long-run specialization: if group $l$ is more specialized that group $l^{\prime}$ initially, $X_{l}^{0}>X_{l^{\prime}}^{0}$, then group $l$ specializes in the long run and the limiting distribution is $\left(X_{A}^{l}, X_{B}^{l}\right)$.

Proof: Consider the equilibrium sequence of occupational distributions:

$$
\left(\left(X_{A}^{1}, X_{B}^{1}\right),\left(X_{A}^{2}, X_{B}^{2}\right), \ldots\right)
$$


If one group $l$ is more specialized than the other group $l^{\prime}$ initially, $X_{l}^{0}>X_{l^{\prime}}^{0}$, supply in (9) requires that the equilibrium sequence begins in one of the following three ways:

$$
\left(\left(X_{l}^{1}, X_{l^{\prime}}^{1}\right),\left(X_{l}^{2}, X_{l^{\prime}}^{2}\right), \ldots\right)=\left\{\begin{array}{l}
((<1,0), \ldots) \\
((1, \geq 0),(1, \geq 0), \ldots) \\
((1, \geq 0),(<1,0), \ldots) .
\end{array}\right.
$$

The proof proceeds by establishing that the sequence converges to $\left(X_{A}^{l}, X_{B}^{l}\right)$ in each of these three cases. Define the variable $\lambda\left(X_{l}\right) \equiv \frac{\theta\left(X_{l}\right)}{X_{l}}$ for $X_{l}>0$. From Assumption 2 it follows that $\lambda^{\prime}\left(X_{l}\right)<0$. Proceed to establish convergence:

Case $1 X_{l}^{1}<1$ and $X_{l^{\prime}}^{1}=0$.

Show first that group $l^{\prime}$ stays out of entrepreneurship for good. By contradiction: if not, then there exists a time $t$ where $X_{l^{\prime}}^{t+1}=0$ and $X_{l^{\prime}}^{t+2}>0$. Since supply must satisfy (10) it then follows that $X_{l}^{t+1}>0$ and $X_{l}^{t+2}=1$. The change in the supply of services can then be written as:

$$
Q_{1}^{t+2}-Q_{1}^{t+1}=N_{l}\left(\theta\left(X_{l}^{t+1}\right)-X_{l}^{t+1} \theta\left(X_{l}^{t}\right)\right)+X_{l^{\prime}}^{t+2} N_{l^{\prime}} \theta\left(X_{l^{\prime}}^{t+1}\right) .
$$

This difference is strictly positive if the first term is positive. Clearly this is the case if $X_{l}^{t+1} \geq X_{l}^{t}$. If, instead, $X_{l}^{t+1}<X_{l}^{t}$, then again focusing on the first term:

$$
\begin{aligned}
\theta\left(X_{l}^{t+1}\right)-X_{l}^{t+1} \theta\left(X_{l}^{t}\right) & =\lambda\left(X_{l}^{t+1}\right) X_{l}^{t+1}-X_{l}^{t+1} \lambda\left(X_{l}^{t}\right) X_{l}^{t} \\
& =X_{l}^{t+1}\left(\lambda\left(X_{l}^{t+1}\right)-\lambda\left(X_{l}^{t}\right) X_{l}^{t}\right)>0 .
\end{aligned}
$$

This establishes that $Q_{1}^{t+2}>Q_{1}^{t+1}$. Since the supply of goods and services must move in the same direction to clear the market, because of perfect complementarity, it follows that the supply of goods also increases from $t+1$ to $t+2$. This in turn requires that the number of workers increases, or equivalently, that the number of entrepreneurs decreases:

$$
X_{l}^{t+2} N_{l}+X_{l^{\prime}}^{t+2} N_{l^{\prime}}<X_{l}^{t+1} N_{l}+X_{l^{\prime}}^{t+1} N_{l^{\prime}}
$$

Since $X_{l}^{t+2}=1$ and $X_{l^{\prime}}^{t+1}=0$, this inequality can be simplified as $N_{l}+X_{l^{\prime}}^{t+2} N_{l^{\prime}}<$ $X_{l}^{t+1} N_{l}$. This inequality is a contradiction and establishes that group $l^{\prime}$ stays out of entrepreneurship for good. The stationary equilibrium must consequently be of the form $\left(X_{l}^{l}, 0\right)$.

Assume first that $X_{l}^{t}>X^{*}$, in which case it is easy to show that $Q_{1}^{t+1}>Q_{1}^{l}>Q_{1}^{t+2}$ as well as $X_{l}^{t+1}<X_{l}^{l}<X_{l}^{t+2}$. Since $Q_{1}^{t+1}>Q_{1}^{t+2}$ it follows that:

$$
\begin{aligned}
X_{l}^{t+1} N_{A} \theta\left(X_{l}^{t}\right) & >X_{l}^{t+2} N_{A} \theta\left(X_{l}^{t+1}\right) \\
X_{l}^{t+1} \lambda\left(X_{l}^{t}\right) X_{l}^{t} & >X_{l}^{t+2} \lambda\left(X_{l}^{t+1}\right) X_{l}^{t+1} \\
X_{l}^{t} \lambda\left(X_{l}^{t}\right) & >X_{l}^{t+2} \lambda\left(X_{l}^{t+1}\right) .
\end{aligned}
$$


The last line implies that $X_{l}^{t}>X_{l}^{t+2}$. The exact same argument, but with reverse inequalities, can be made for $X_{l}^{t}<X_{l}^{l}$. Therefore, having established that $X_{l}^{t}>$ $X_{l}^{t+2}>X_{l}^{l}$ when $X_{l}^{t}>X_{l}^{l}$, and vice versa when $X_{l}^{t}<X_{l}^{l}$, it has been shown that $X_{l}^{t}$ approaches the stationary equilibrium value $X_{l}^{l}$ over time. This establishes convergence in Case 1.

Case $2 X_{l}^{1}=1, X_{l^{\prime}}^{1} \geq 0, X_{l}^{2}=1$ and $X_{l^{\prime}}^{2} \geq 0$.

Show first that in this case, group $l$ stays specialized for good. By contradiction: if not, then there exists a time $t$ when $X_{l}^{t}=1, X_{l}^{t+1}=1$ and $X_{l}^{t+2}<1$. Since supply must satisfy (10), it follows that $X_{l^{\prime}}^{t+2}=0$. The change in the supply of services can be written as

$$
Q_{1}^{t+2}-Q_{1}^{t+1}=N_{l}\left(X_{l}^{t+2} \theta(1)-\theta(1)\right)-X_{l^{\prime}}^{t+1} N_{l^{\prime}} \theta\left(X_{l}^{t}\right)<0 .
$$

Since the supply of goods and services must move in the same direction to clear the market, it follows that the supply of goods also decreases, which requires that the number of entrepreneurs increases:

$$
X_{l}^{t+2} N_{l}+X_{l^{\prime}}^{t+2} N_{l^{\prime}}>X_{l}^{t+1} N_{l}+X_{l^{\prime}}^{t+1} N_{l^{\prime}}
$$

Since $X_{l^{\prime}}^{t+2}=0$ and $X_{l}^{t+1}=1$, this inequality can be rewritten as $X_{l}^{t+2} N_{l}>N_{l}+$ $X_{l^{\prime}}^{t+1} N_{l^{\prime}}$, which is a contradiction. This establishes that group $l$ stays specialized in entrepreneurship for good. The stationary equilibrium must consequently be of the form $\left(1, X_{l^{\prime}}^{l}\right)$. By the same argument as in Case 1, the sequence can be shown to approach the stationary equilibrium value $X_{l^{\prime}}^{l}$ over time, both if $X_{l^{\prime}}^{t}>X_{l^{\prime}}^{l}$ and if $X_{l^{\prime}}^{t}<X_{l^{\prime}}^{l}$. This establishes convergence in Case 2.

Case $3 X_{l}^{1}=1$ and $X_{l^{\prime}}^{1} \geq 0$ and $X_{l}^{2}<1$ and $X_{l^{\prime}}^{2}=0$.

By the same argument in Case 1, it follows that group $l^{\prime}$ stays out of entrepreneurship permanently. Repeating the arguments in Case 1, convergence can then be established also in Case 3.

Consequently, in all three cases there is convergence.

\subsection{Proof: Assortative Matching}

Show that the efficient one-sided matching is assortative. The matching function $v$ is symmetric and the cross-derivative positive. For traits $t_{1}<t_{2}<t_{3}<t_{4}$, show that the only efficient matching is $\left(t_{1}, t_{2}\right)$ and $\left(t_{3}, t_{4}\right)$. As in Becker (1973), use a property of $v$ when the cross-derivative is positive

$$
v(a, d)+v(c, b)<v(a, b)+v(c, d)
$$


for $a<c$ and $b<d$. Take an arbitrary efficient matching $\left(x_{1}, x_{2}\right)$ and $\left(x_{3}, x_{4}\right)$, which is a permutation of the traits $t_{1}, t_{2}, t_{3}$ and $t_{4}$. Without loss of generality, relabel these traits pairwise so that $x_{1}<x_{2}$ and $x_{3}<x_{4}$. Also without loss of generality, relabel the pairs so that $x_{1}<x_{3}$. This implies that $x_{1}<x_{3}<x_{4}$. Using the symmetry of $v$, the aggregate utility from the arbitrary efficient matching can be written as $v\left(x_{1}, x_{2}\right)+v\left(x_{4}, x_{3}\right)$. Since $x_{1}<x_{4}$ it follows from (33) that $x_{2}<x_{3}$, otherwise aggregate utility could be increased by interchanging $x_{2}$ and $x_{3}$, just as $b$ and $d$ were interchanged in (33). Consequently, with $x_{1}<x_{2}<x_{3}<x_{4}$, the arbitrarily chosen efficient matching $\left(x_{1}, x_{2}\right)$ and $\left(x_{3}, x_{4}\right)$ is identical to the efficient matching $\left(t_{1}, t_{2}\right)$ and $\left(t_{3}, t_{4}\right)$.

\subsection{Formalized Intuition for Why There are No Splinter Groups}

To see why there are no splinter groups, consider a branching tree tracing relationships in the population. Let $\Sigma$ be the set of all families. Define an arbitrary family in $\Sigma$ as the singleton set $\sigma(0)$. Let $\sigma(1)$ be the set of families in $\Sigma / \sigma(0)$ with at least one family member married to someone in the original family $\sigma(0)$. Define $\sigma(2)$ as the set of families in $\Sigma /(\sigma(0) \cup \sigma(1))$ with at least one family member married to someone in $\sigma(1)$. Continuing by iteration to more and more distant relations, let $\sigma(r)$ be the set of families in $\Sigma /(\sigma(r-2) \cup \sigma(r-1))$ married to someone in $\sigma(r-1)$. The variable $r$ denotes what is sometimes called the degree of separation between the initial family $\sigma(0)$ and the families in $\sigma(r)$. The degree of separation is a measure of the social distance between individuals; compare Milgram (1967). The collection of these sets, $\cup_{q=0}^{r} \sigma(q)$, constitutes a branching tree. The sets in this collection are mutually exclusive, but if there are splinter groups, the sets are not exhaustive even as $r \rightarrow \infty$. Denote by $s(r)$ the cardinality of the set $\sigma(r)$. Since each family in $\sigma(r)$ is composed of $d$ family members, where at least one member in each family by definition is married into $\sigma(r-1)$, the expansion of the tree $\cup_{q=0}^{r} \sigma(q)$ is bounded by

$$
s(r+1) \leq s(r)(d-1) \text {. }
$$

If equation (34) holds with equally, then as $r$ increases $s(r)$ very soon encompasses the entire population. It turns out that the equation generally holds as an inequality, however. The reason for this slowdown is threefold. First, a person in $\sigma(r)$ could marry another person in $\sigma(r)$. Second, a family in $\sigma(r)$ could have more than one family member married to someone in $\sigma(r-1)$. Thirdly, several people in $\sigma(r)$ could marry into the same family. These three types of events combine to prevent each family in $\sigma(r)$ from contributing a full $d-1$ new families to $\sigma(r+1)$, and consequently cause (34) to hold as an inequality.

Applying the branching tree $\cup_{q=0}^{r} \sigma(q)$ to the efficient assortative matching, the branching tree is overwhelmingly likely to grow to encompass the entire population in 
the limit. Since the branching tree only expands to include people who are directly or indirectly related, this limit result is equivalent to Proposition 5 that there are no splinter groups. To see why the entire population is included in the limit, consider what would happen if it were not true, if the branching tree died out without having reached a positive fraction of the population. If this were the case, then $\sigma(r)$ would eventually have to grow arbitrarily small relative to the remainder set $\Sigma /(\sigma(r-2) \cup \sigma(r-1))$, and therefore the likelihood that someone in $\sigma(r)$ married someone else in $\sigma(r)$ rather than in the remainder set, or that several people in $\sigma(r-1)$ married into the same family in $\sigma(r)$ rather than in the remainder set, or that several people in $\sigma(r)$ married into the same family in the remainder set, must also grow arbitrarily small. But then equation (34) should hold as an equality, implying that $s(r+1)>s(r)$, which contradicts the premise that the branching tree died out without having reached the entire population. Consequently, everyone in the population is either directly or indirectly related, and there are no splinter groups. The formal proof is below.

\subsection{Proof: No Splinter Groups}

Proposition 5 The likelihood that splinter groups exist is zero.

Proof: Define a $d$-regular multigraph with loops, where every vertex corresponds to a family, and every edge corresponds to a marriage. A splinter group is equivalent to an unconnected component of this graph. Assortative marriages on independent traits generate a random configuration of vertices. A random configuration is equivalent to a regular random multigraph, as defined in Janson (2000). A regular random multigraph is asymptotically almost surely Hamilitonian for $d>3$, Janson (2000). Connectivity follows from Hamilitonicity, which rules out the existence of unconnected components, and consequently, the existence of splinter groups.

This proof most likely also goes through for $d \geq 3$, since it really only needs connectivity and since connectivity is closely related to cubic graphs. The fourth edge is necessary in the case of multigraphs to ensure Hamiltonicity, but Hamiltonicity is stronger than connectivity. 


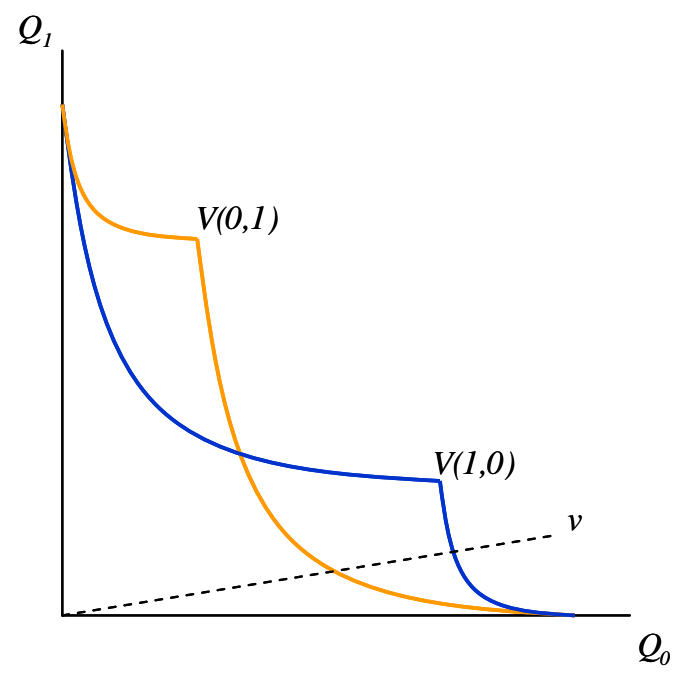

Figure 1: Production possibilities with specialized occupational distributions. The ray $v$ is the preference parameter over goods in the Leontief utility function. Along the curve with the kink $V(1,0)$, all entrepreneurs belong to group $A$ (below the kink) or all members of group $A$ are entrepreneurs (above). Similarly, along the curve with the kink $V(0,1)$, all entrepreneurs belong to group $B$ (below) or all members of group $B$ are entrepreneurs (above).

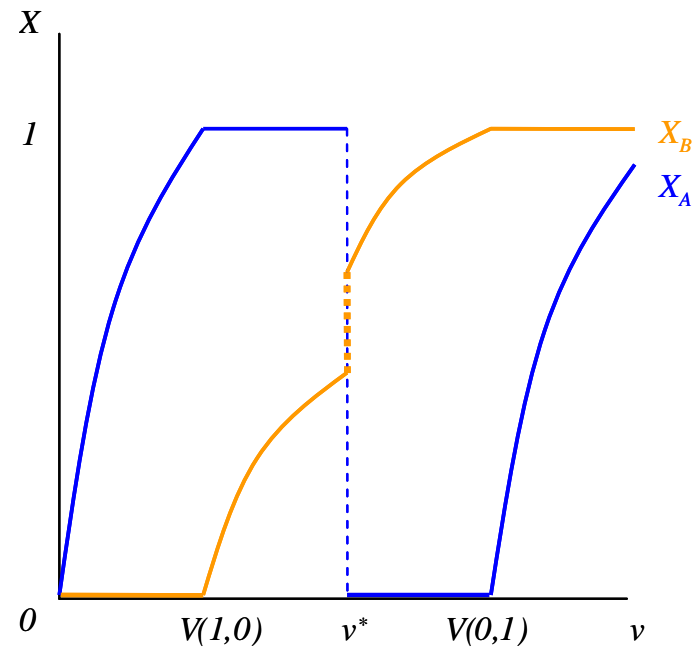

Figure 2. The efficient occupational distribution for different values of $\mathrm{v}$. The minority group $A$ specializes as entrepreneurs so long as the entrepreneurial sector is small enough. 


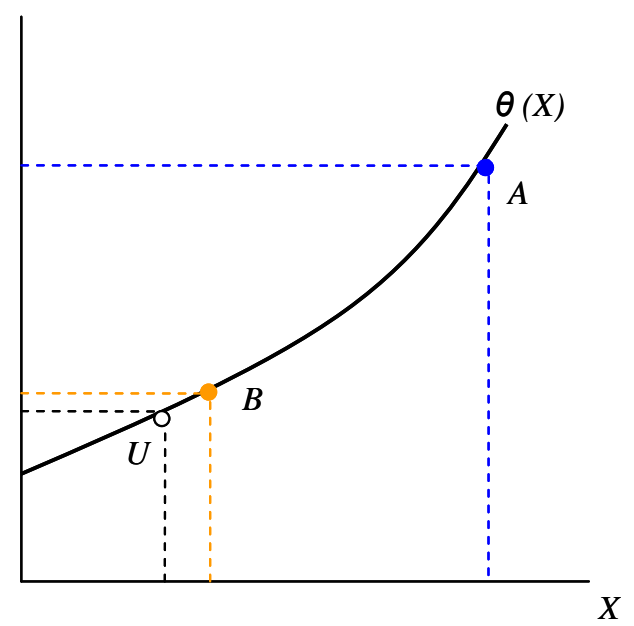

Figure 3. Individual productivity and the three stationary equilibria: one specialized equilibrium with minority specialization (A), one specialized equilibrium with majority specialization (B), and one unstratified equilibrium $(\mathrm{U})$.

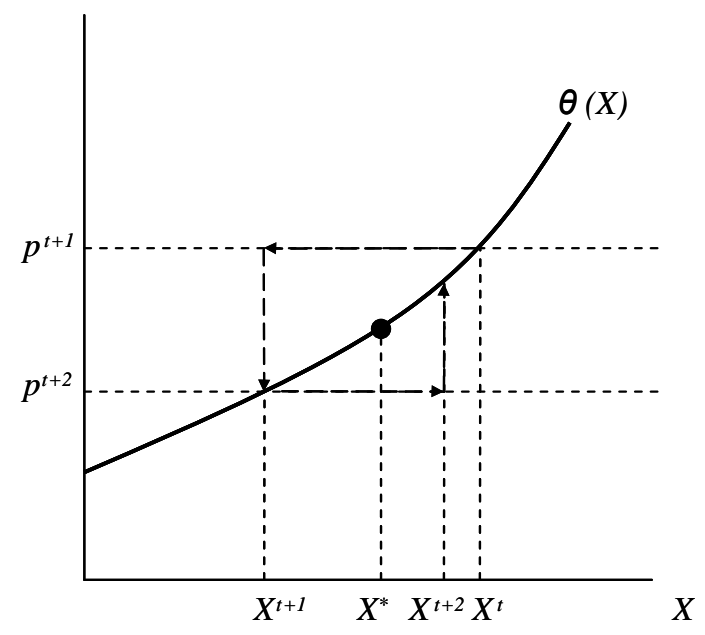

Figure 4. Stable dynamics when the internal effect dominates. 


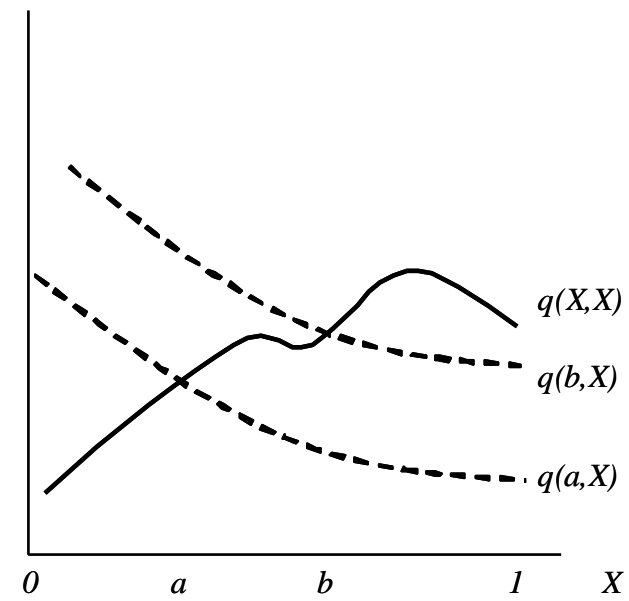

Figure 5. Sorting versus interaction effects in individual productivity. The dotted lines illustrate how the interaction effect raises productivity at all ability levels when specialization increases from $a$ to $b$. The solid line shows the productivity of the marginal entrepreneur, for whom $i=X$ at every level of $X$.

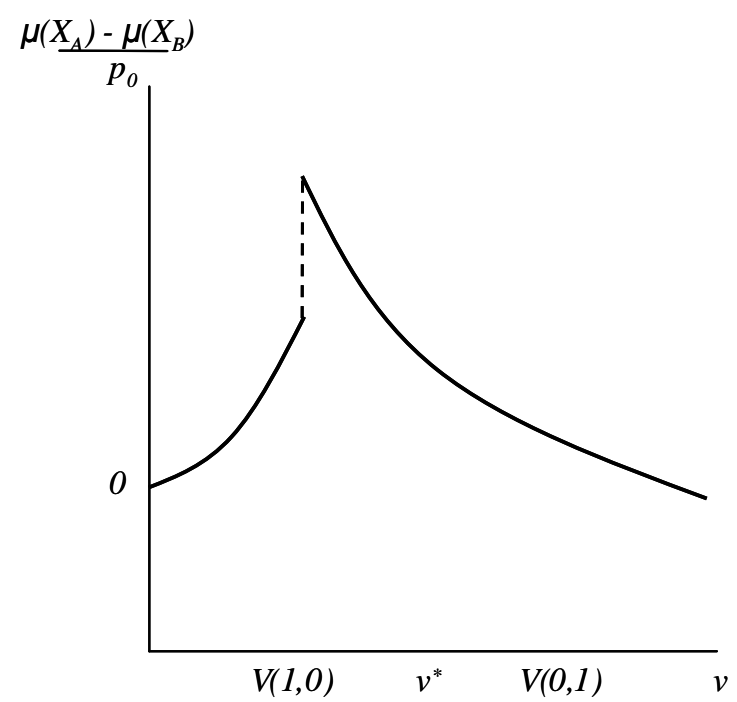

Figure 6. The difference in mean earnings between group $A$ and group $B$, for different values of $v$, when minority group $A$ specializes. 
Table 1a: Ethnic groups displaying the greatest self-employment industrial concentration

\begin{tabular}{|c|c|c|c|c|c|c|}
\hline $\begin{array}{l}\text { Ethnic group, } \\
\text { designated by } \\
\text { country of origin or } \\
\text { sub-groups available } \\
\text { in IPUMS }\end{array}$ & $\begin{array}{c}\text { Weighted } \\
\text { average } \\
\text { overage ratio } \\
\text { over all } \\
\text { industries }\end{array}$ & $\begin{array}{l}\text { Weighted average } \\
\text { overage ratio for three } \\
\text { largest self- } \\
\text { employment } \\
\text { industries for ethnicity }\end{array}$ & $\begin{array}{l}\text { Self-employment industry with max } \\
\text { overage ratio }\end{array}$ & $\begin{array}{c}\text { Total } \\
\text { employment } \\
\text { in sample }\end{array}$ & $\begin{array}{l}\text { Share of } \\
\text { employment } \\
\text { classified as } \\
\text { self- } \\
\text { employed }\end{array}$ & $\begin{array}{l}\text { In-marriage } \\
\text { rate }\end{array}$ \\
\hline Yemen & 50.0 & 64.2 & Grocery stores & 2,322 & $26 \%$ & $86 \%$ \\
\hline Eritrea & 35.4 & 45.5 & Taxicab service & 3,338 & $17 \%$ & $100 \%$ \\
\hline Gujarati & 32.8 & 59.4 & Hotels and motels & 26,373 & $25 \%$ & $93 \%$ \\
\hline Ethiopia & 27.2 & 43.9 & Taxicab service & 8,760 & $14 \%$ & $64 \%$ \\
\hline Bangladesh & 20.5 & 27.6 & Taxicab service & 11,770 & $16 \%$ & $86 \%$ \\
\hline Chaldean & 16.1 & 35.0 & Grocery stores & 5,429 & $33 \%$ & $88 \%$ \\
\hline Haiti & 16.1 & 29.8 & Taxicab service & 58,971 & $8 \%$ & $75 \%$ \\
\hline Ghana & 15.9 & 20.6 & Taxicab service & 10,975 & $11 \%$ & $68 \%$ \\
\hline Afghanistan & 15.3 & 20.9 & Taxicab service & 6,432 & $24 \%$ & $76 \%$ \\
\hline Nigeria & 13.6 & 29.5 & Taxicab service & 27,232 & $18 \%$ & $64 \%$ \\
\hline Tonga & 12.0 & 14.5 & Landscape and horticultural services & 2,685 & $27 \%$ & $77 \%$ \\
\hline Morocco & 11.3 & 11.2 & Construction & 5,346 & $23 \%$ & $32 \%$ \\
\hline Punjabi & 10.5 & 21.8 & Gasoline service stations & 16,453 & $27 \%$ & $96 \%$ \\
\hline Jordan & 10.0 & 17.6 & Grocery stores & 7,674 & $35 \%$ & $68 \%$ \\
\hline Laos & 9.9 & 3.6 & Agricultural production, crops & 19,635 & $9 \%$ & $77 \%$ \\
\hline Pakistan & 9.9 & 18.5 & Taxicab service & 35,722 & $22 \%$ & $83 \%$ \\
\hline Dominican Republic & 8.7 & 16.6 & Taxicab service & 70,576 & $13 \%$ & $62 \%$ \\
\hline Cambodia & 8.5 & 7.8 & Eating and drinking places & 16,245 & $15 \%$ & $82 \%$ \\
\hline Iraq & 8.5 & 3.4 & Offices and clinics of physicians & 4,598 & $32 \%$ & $60 \%$ \\
\hline Turkey & 8.1 & 3.4 & Eating and drinking places & 10,438 & $27 \%$ & $60 \%$ \\
\hline Korea & 8.0 & 15.0 & Laundry, cleaning, and garment services & 91,928 & $45 \%$ & $70 \%$ \\
\hline Australia & 7.9 & 2.1 & Construction & 4,910 & $23 \%$ & $32 \%$ \\
\hline Hungary & 7.6 & 3.1 & Construction & 6,697 & $26 \%$ & $32 \%$ \\
\hline Syria & 7.5 & 11.0 & Offices and clinics of physicians & 7,623 & $41 \%$ & $57 \%$ \\
\hline Sri Lanka (Ceylon) & 7.3 & 9.1 & Offices and clinics of physicians & 4,010 & $26 \%$ & $50 \%$ \\
\hline
\end{tabular}

Notes: Descriptive statistics from 2000 Census IPUMS. Sample includes males immigrating after 1968 (effective date of the Immigration Reform Act of 1965), aged 30-65 in 2000, and living in the United States for at least 10 years. Sample excludes workers whose self-employment status is unknown or not applicable, industries without self-employment, and workers living outside of metropolitan areas. The overage ratios and industry titles are specific to self-employment and weight industries by the number of self-employed workers for the ethnic group. Two small groups that are partially composed of residual individuals are not listed in this table but have overage values in this range (Indochina, ns 9.4; Africa, ns/nec 8.2). The employment column displays the total workforce size included in the sample for each ethnic group. 
Table 1b: Maximum overage clusters and industry employment ranks by ethnic group

\begin{tabular}{|c|c|c|c|c|c|c|c|}
\hline Ethnic group & $\begin{array}{l}\text { Industry of max overage for self- } \\
\text { employed sample }\end{array}$ & Index & $\begin{array}{l}\text { Industry } \\
\text { size }\end{array}$ & $\begin{array}{l}\text { Industry of max overage for total } \\
\text { worker sample }\end{array}$ & $\begin{array}{l}\text { Industry } \\
\text { size }\end{array}$ & Industry of max total employment & $\begin{array}{l}\text { Industry } \\
\text { size }\end{array}$ \\
\hline Gujarati & Hotels and motels & 108.1 & 31 & Liquor stores & 146 & Hotels and motels & 31 \\
\hline Yemen & Grocery stores & 75.0 & 13 & Grocery stores & 13 & Grocery stores & 13 \\
\hline Eritrea & Taxicab service & 61.0 & 77 & Taxicab service & 77 & Taxicab service & 77 \\
\hline Ethiopia & Taxicab service & 52.6 & 77 & Taxicab service & 77 & Taxicab service & 77 \\
\hline Bangladesh & Taxicab service & 47.1 & 77 & Taxicab service & 77 & Eating and drinking places & 4 \\
\hline Haiti & Taxicab service & 42.3 & 77 & Taxicab service & 77 & Construction & 1 \\
\hline Nigeria & Taxicab service & 38.1 & 77 & Taxicab service & 77 & Hospitals & 5 \\
\hline Ghana & Taxicab service & 35.3 & 77 & Taxicab service & 77 & Hospitals & 5 \\
\hline Punjabi & Gasoline service stations & 34.6 & 88 & Taxicab service & 77 & Taxicab service & 77 \\
\hline Korea & Laundry, cleaning, etc. services & 33.5 & 94 & Shoe repair shops & 200 & Laundry, cleaning, etc. services & 94 \\
\hline Afghanistan & Taxicab service & 32.5 & 77 & Taxicab service & 77 & Eating and drinking places & 4 \\
\hline Jordan & Grocery stores & 28.1 & 13 & Taxicab service & 77 & Grocery stores & 13 \\
\hline Dom. Republic & Taxicab service & 27.2 & 77 & Taxicab service & 77 & Construction & 1 \\
\hline Armenian & Jewelry stores & 25.7 & 138 & Jewelry stores & 138 & Construction & 1 \\
\hline Pakistan & Taxicab service & 25.6 & 77 & Taxicab service & 77 & Taxicab service & 77 \\
\hline Lebanon & Gasoline service stations & 23.5 & 88 & Gasoline service stations & 88 & Eating and drinking places & 4 \\
\hline Chaldean & Grocery stores & 20.6 & 13 & Liquor stores & 146 & Grocery stores & 13 \\
\hline Tonga & Landscape/horticultural services & 18.2 & 25 & Landscape/horticultural services & 25 & Construction & 1 \\
\hline India & Hotels and motels & 17.8 & 31 & Offices and clinics of physicians & 36 & Computer and data processing & 8 \\
\hline Portugal & Fishing, hunting, and trapping & 16.5 & 170 & Dyeing and finishing textiles & 176 & Construction & 1 \\
\hline Ecuador & Taxicab service & 15.6 & 77 & Apparel and accessories & 106 & Construction & 1 \\
\hline Iran & Apparel, fabrics, and notions & 14.3 & 144 & Apparel, fabrics, and notions & 144 & Eating and drinking places & 4 \\
\hline Vietnam & Fishing, hunting, and trapping & 13.4 & 170 & Fishing, hunting, and trapping & 170 & Electrical machinery/equipment & 14 \\
\hline USSR/Russia & Taxicab service & 13.2 & 77 & Taxicab service & 77 & Construction & 1 \\
\hline Ukraine & Taxicab service & 13.2 & 77 & Taxicab service & 77 & Construction & 1 \\
\hline
\end{tabular}

Notes: See Table 1a. Table is ordered by the 25 largest self-employment overage ratios at the industry level for ethnic groups. The industry size variable ranks industries from largest (1) to smallest (200). The table also displays for each ethnic group the industry of maximum overage when considering all employed workers and the industry where the greatest number of workers are employed. 
Table 2: OLS estimations for log weighted average overage ratio for ethnic groups

\begin{tabular}{|c|c|c|c|c|c|c|c|c|}
\hline & $\begin{array}{l}\text { Baseline } \\
\text { estimation }\end{array}$ & $\begin{array}{l}\text { Without } \\
\text { sample } \\
\text { weights }\end{array}$ & $\begin{array}{c}\text { Without } \\
\text { winsorization }\end{array}$ & $\begin{array}{l}\text { Including } \\
\text { fixed effects } \\
\text { for origin } \\
\text { continent }\end{array}$ & $\begin{array}{l}\text { Using } \\
\text { median } \\
\text { regression } \\
\text { format }\end{array}$ & $\begin{array}{c}\text { Using } \\
\text { bootstrapped } \\
\text { standard } \\
\text { errors }\end{array}$ & $\begin{array}{l}\text { Including } \\
\text { simulated } \\
\text { overage } \\
\text { control1 }\end{array}$ & $\begin{array}{c}\text { Including } \\
\text { simulated } \\
\text { overage } \\
\text { control2 }\end{array}$ \\
\hline & $(1)$ & $(2)$ & (3) & (4) & $(5)$ & $(6)$ & (7) & (8) \\
\hline $\begin{array}{l}\text { Inverse of log ethnic group size } \\
\text { (small groups have larger values) }\end{array}$ & $\begin{array}{c}0.634 \\
(0.069)\end{array}$ & $\begin{array}{c}0.630 \\
(0.067)\end{array}$ & $\begin{array}{c}0.629 \\
(0.062)\end{array}$ & $\begin{array}{c}0.552 \\
(0.070)\end{array}$ & $\begin{array}{c}0.586 \\
(0.092)\end{array}$ & $\begin{array}{c}0.630 \\
(0.070)\end{array}$ & $\begin{array}{c}0.509 \\
(0.188)\end{array}$ & $\begin{array}{c}0.524 \\
(0.182)\end{array}$ \\
\hline Log isolation of ethnic group & $\begin{array}{c}0.519 \\
(0.067)\end{array}$ & $\begin{array}{c}0.521 \\
(0.065)\end{array}$ & $\begin{array}{c}0.511 \\
(0.066)\end{array}$ & $\begin{array}{c}0.485 \\
(0.091)\end{array}$ & $\begin{array}{c}0.529 \\
(0.091)\end{array}$ & $\begin{array}{c}0.521 \\
(0.070)\end{array}$ & $\begin{array}{c}0.550 \\
(0.070)\end{array}$ & $\begin{array}{c}0.538 \\
(0.067)\end{array}$ \\
\hline Log predicted overage1 & & & & & & & $\begin{array}{c}0.155 \\
(0.195)\end{array}$ & \\
\hline Log predicted overage 2 & & & & & & & & $\begin{array}{c}0.123 \\
(0.186)\end{array}$ \\
\hline R-Squared value & 0.612 & 0.626 & 0.629 & 0.650 & 0.428 & 0.626 & 0.577 & 0.612 \\
\hline
\end{tabular}

Notes: Estimations describe the OLS relationship between industry concentration for ethnic entrepreneurship and ethnic group size and in-marriage isolation. The outcome variable is the log weighted average overage ratio across industries for each ethnic group, where the weights are levels of self employment in each industry per group. Variables are winsorized at their 10\%/90\% levels and transformed to have unit standard deviation for interpretation. Regressions are weighted by log ethnic group employee counts in MSAs, include 77 observations, and report robust standard errors. Columns 2-6 provide robustness checks on the baseline specification. Regressions in Columns 5 and 6 are unweighted and should be referenced against Column 2. Column 5 reports pseudo R-squared values. Columns 7 and 8 include control variables for predicted overage ratios based upon 1000 Monte Carlo simulations. In these simulations, pools of similarly sized ethnic groups to our true sample are formed and randomly assigned industry and entrepreneurship status according to national propensities. From these random assignments, we calculate 1000 overage metrics for each ethnic group that exactly mirror our primary data construction. The average of these simulations is entered as a control variable. In the first version included in Column 7, self-employment status and industry status are separately randomized, such that we overall predict roughly the same self-employment rate in each industry. In the second version included in Column 8 , self-employment status and industry are jointly drawn such that we overall replicate observed self-employment levels across industries. 
Table 3: OLS estimations with alternative metric designs

\begin{tabular}{|c|c|c|c|c|c|c|c|}
\hline & \multicolumn{5}{|c|}{ Log weighted average overage across all industries } & \multirow{2}{*}{$\begin{array}{l}\text { Log average } \\
\text { of three } \\
\text { largest } \\
\text { overage } \\
\text { ratios for } \\
\text { ethnic group }\end{array}$} & \multirow[b]{2}{*}{$\begin{array}{l}\text { Log largest } \\
\text { overage ratio } \\
\text { for ethnic } \\
\text { group }\end{array}$} \\
\hline & $\begin{array}{l}\text { Baseline } \\
\text { estimation }\end{array}$ & $\begin{array}{l}\text { Using three } \\
\text { largest } \\
\text { industries for } \\
\text { ethnic group }\end{array}$ & $\begin{array}{l}\text { Using total } \\
\text { worker } \\
\text { sample }\end{array}$ & $\begin{array}{c}\text { Excluding } \\
\text { natives from } \\
\text { denominator } \\
\text { shares }\end{array}$ & $\begin{array}{l}\text { Including } \\
\text { rural workers }\end{array}$ & & \\
\hline & $(1)$ & $(2)$ & $(3)$ & $(4)$ & $(5)$ & $(6)$ & $(7)$ \\
\hline $\begin{array}{l}\text { Inverse of log ethnic group size } \\
\text { (small groups have larger values) }\end{array}$ & $\begin{array}{c}0.634 \\
(0.069)\end{array}$ & $\begin{array}{c}0.375 \\
(0.080)\end{array}$ & $\begin{array}{c}0.595 \\
(0.073)\end{array}$ & $\begin{array}{c}0.398 \\
(0.080)\end{array}$ & $\begin{array}{c}0.602 \\
(0.072)\end{array}$ & $\begin{array}{c}0.130 \\
(0.076)\end{array}$ & $\begin{array}{c}0.068 \\
(0.076)\end{array}$ \\
\hline Log isolation of ethnic group & $\begin{array}{c}0.519 \\
(0.067)\end{array}$ & $\begin{array}{c}0.640 \\
(0.072)\end{array}$ & $\begin{array}{c}0.514 \\
(0.066)\end{array}$ & $\begin{array}{c}0.578 \\
(0.083)\end{array}$ & $\begin{array}{c}0.529 \\
(0.068)\end{array}$ & $\begin{array}{c}0.722 \\
(0.070)\end{array}$ & $\begin{array}{c}0.706 \\
(0.075)\end{array}$ \\
\hline R-Squared value & 0.61 & 0.51 & 0.525 & 0.470 & 0.585 & 0.533 & 0.508 \\
\hline
\end{tabular}

Notes: See Table 2. Regressions in Columns 2-5 provide robustness checks on the core metric. Column 2 restricts the overage measure to just the three largest self-employment industries for an ethnic group, Column 3 considers the metric that uses all employed workers for the ethnic group, Column 4 compares industry-level overages only to rates of other immigrant groups, and Column 5 includes rural workers in the sample. Columns 6-7 consider extreme values among industries by ethnic group. These latter overages are done without reference to industry importance in terms of ethnic group selfemployment, but they do require at least ten observations exist for an ethnic group - industry cluster to be included. 
Table 4: OLS relationships with non-parametric forms

\begin{tabular}{|c|c|c|c|c|}
\hline & $\begin{array}{l}\text { Log weighted average } \\
\text { overage across all } \\
\text { industries }\end{array}$ & $\begin{array}{l}\text { Log weighted average } \\
\text { overage across three } \\
\text { largest industries }\end{array}$ & $\begin{array}{l}\text { Log average of three } \\
\text { largest overage ratios for } \\
\text { ethnic group }\end{array}$ & $\begin{array}{l}\text { Log largest overage ratio } \\
\text { for ethnic group }\end{array}$ \\
\hline & $(1)$ & $(2)$ & $(2)$ & $(3)$ \\
\hline $\begin{array}{l}(0,1) \text { ethnic size in smallest third } x \\
(0,1) \text { ethnic isolation in highest third }\end{array}$ & $\begin{array}{c}2.472 \\
(0.188)\end{array}$ & $\begin{array}{c}2.276 \\
(0.168)\end{array}$ & $\begin{array}{l}1.826 \\
(0.155)\end{array}$ & $\begin{array}{c}1.572 \\
(0.180)\end{array}$ \\
\hline $\begin{array}{l}(0,1) \text { ethnic size in smallest third } \mathrm{x} \\
(0,1) \text { ethnic isolation in middle third }\end{array}$ & $\begin{array}{c}1.514 \\
(0.271)\end{array}$ & $\begin{array}{c}0.753 \\
(0.380)\end{array}$ & $\begin{array}{c}0.416 \\
(0.368)\end{array}$ & $\begin{array}{c}0.375 \\
(0.362)\end{array}$ \\
\hline $\begin{array}{l}(0,1) \text { ethnic size in smallest third } \mathrm{x} \\
(0,1) \text { ethnic isolation in lowest third }\end{array}$ & $\begin{array}{l}1.048 \\
(0.280)\end{array}$ & $\begin{array}{c}0.280 \\
(0.273)\end{array}$ & $\begin{array}{l}-0.654 \\
(0.243)\end{array}$ & $\begin{array}{l}-1.002 \\
(0.251)\end{array}$ \\
\hline $\begin{array}{l}(0,1) \text { ethnic size in middle third } \mathrm{x} \\
(0,1) \text { ethnic isolation in highest third }\end{array}$ & $\begin{array}{c}1.581 \\
(0.322)\end{array}$ & $\begin{array}{c}1.211 \\
(0.374)\end{array}$ & $\begin{array}{c}1.127 \\
(0.253)\end{array}$ & $\begin{array}{c}1.044 \\
(0.260)\end{array}$ \\
\hline $\begin{array}{l}(0,1) \text { ethnic size in middle third } \mathrm{x} \\
(0,1) \text { ethnic isolation in middle third }\end{array}$ & $\begin{array}{c}0.908 \\
(0.313)\end{array}$ & $\begin{array}{c}0.573 \\
(0.314)\end{array}$ & $\begin{array}{c}0.351 \\
(0.345)\end{array}$ & $\begin{array}{c}0.338 \\
(0.362)\end{array}$ \\
\hline $\begin{array}{l}(0,1) \text { ethnic size in middle third } \mathrm{x} \\
(0,1) \text { ethnic isolation in lowest third }\end{array}$ & $\begin{array}{c}0.428 \\
(0.228)\end{array}$ & $\begin{array}{l}-0.038 \\
(0.220)\end{array}$ & $\begin{array}{l}-0.443 \\
(0.276)\end{array}$ & $\begin{array}{l}-0.542 \\
(0.306)\end{array}$ \\
\hline $\begin{array}{l}(0,1) \text { ethnic size in largest third } \mathrm{x} \\
(0,1) \text { ethnic isolation in highest third }\end{array}$ & $\begin{array}{c}0.802 \\
(0.369)\end{array}$ & $\begin{array}{c}0.944 \\
(0.361)\end{array}$ & $\begin{array}{c}0.927 \\
(0.309)\end{array}$ & $\begin{array}{c}0.767 \\
(0.300)\end{array}$ \\
\hline $\begin{array}{l}(0,1) \text { ethnic size in largest third } \mathrm{x} \\
(0,1) \text { ethnic isolation in middle third }\end{array}$ & $\begin{array}{c}0.126 \\
(0.312)\end{array}$ & $\begin{array}{c}0.279 \\
(0.334)\end{array}$ & $\begin{array}{c}0.329 \\
(0.297)\end{array}$ & $\begin{array}{c}0.294 \\
(0.299)\end{array}$ \\
\hline $\begin{array}{l}(0,1) \text { ethnic size in largest third } \mathrm{x} \\
(0,1) \text { ethnic isolation in lowest third }\end{array}$ & \multicolumn{4}{|c|}{ Excluded group } \\
\hline R-Squared value & 0.57 & 0.49 & 0.55 & 0.54 \\
\hline
\end{tabular}

Notes: See Table 3. Effects are measured relative to largest and least isolated ethnic groups. 
Table 5: Baseline IV estimations

Instrumenting with 1980 ethnic group size and in-marriage rates in United States

$\begin{array}{ccc}\begin{array}{c}\text { First stage for } \\ \text { group size }\end{array} & \begin{array}{c}\text { First stage for } \\ \text { group isolation }\end{array} & \begin{array}{c}\text { Second stage } \\ \text { results }\end{array}\end{array}$

Instrumenting with predicted ethnic group size from gravity model and in-marriage rates in

United Kingdom

\begin{tabular}{ccc}
\hline $\begin{array}{c}\text { First stage for } \\
\text { group size }\end{array}$ & $\begin{array}{l}\text { First stage for } \\
\text { group isolation }\end{array}$ & $\begin{array}{c}\text { Second stage } \\
\text { results }\end{array}$ \\
\hline
\end{tabular}

(1)

(2)

(3)

(4)

(5)

(6)

\section{Instrument for size}

0.877

$-0.063$

$(0.044)$

(0.055)

0.706

(0.069)

$-0.018$

$-0.075$

0.721

(0.043)

(0.114)

$-0.142$

(0.109)

(0.115)

Instrument for isolation

$\begin{array}{cc}\text { F stat }= & \text { Bias }= \\ 23.6 & <10 \%\end{array}$

Inverse of log ethnic group size

$\mathrm{F}$ stat $=$

35.5

0.587

(0.078)

(0.077)

0.487

0.516

(0.099)

Log isolation of ethnic group

0.034

Exogeneity test p-value

Notes: See Table 2. Estimations describe the IV relationship between industry concentration for ethnic entrepreneurship and ethnic group size and inmarriage isolation. The column headers indicate the instruments used. The 2SLS relative bias reports the minimum bias that can be specified and still reject the null hypothesis that the instruments are weak. This level is determined through the minimum eigenvalue statistic and Stock and Yogo's (2005) 2SLS size of nominal 5\% Wald test. The null hypothesis in Wu-Hausman exogeneity tests is that the instrumented regressors are exogenous. The test statistic used is robust to clustering of standard errors. Regressions cluster standard errors by the 43 and 24 ethnic groups in the US 1980 and UK 1990 datasets used to build the respective instruments. 
Table 6: Robustness checks on IV estimations for log weighted average overage ratio for ethnic groups

\begin{tabular}{|c|c|c|c|c|c|c|c|c|}
\hline & \multirow[b]{2}{*}{$\begin{array}{l}\text { Baseline } \\
\text { estimation }\end{array}$} & \multirow[b]{2}{*}{$\begin{array}{l}\text { Without } \\
\text { sample } \\
\text { weights }\end{array}$} & \multirow[b]{2}{*}{$\begin{array}{c}\text { Without } \\
\text { winsorization }\end{array}$} & \multirow[b]{2}{*}{$\begin{array}{c}\text { Using } \\
\text { bootstrapped } \\
\text { standard } \\
\text { errors }\end{array}$} & \multicolumn{2}{|c|}{ Isolation IV Only } & \multicolumn{2}{|c|}{ Double IV } \\
\hline & & & & & $\begin{array}{c}\text { Including } \\
\text { simulated } \\
\text { overage } \\
\text { control1 }\end{array}$ & $\begin{array}{c}\text { Including } \\
\text { simulated } \\
\text { overage } \\
\text { control2 }\end{array}$ & $\begin{array}{l}\text { Including } \\
\text { simulated } \\
\text { overage } \\
\text { control1 }\end{array}$ & $\begin{array}{c}\text { Including } \\
\text { simulated } \\
\text { overage } \\
\text { control2 }\end{array}$ \\
\hline & $(1)$ & $(2)$ & $(3)$ & $(4)$ & $(5)$ & $(6)$ & $(7)$ & $(8)$ \\
\hline & \multicolumn{8}{|c|}{ A. IV results using 1980 ethnic group size and in-marriage rates in United States } \\
\hline $\begin{array}{l}\text { Inverse of log ethnic group size } \\
\text { (small groups have larger values) }\end{array}$ & $\begin{array}{c}0.757 \\
(0.077)\end{array}$ & $\begin{array}{c}0.748 \\
(0.072)\end{array}$ & $\begin{array}{c}0.689 \\
(0.084)\end{array}$ & $\begin{array}{c}0.748 \\
(0.085)\end{array}$ & $\begin{array}{c}0.519 \\
(0.232)\end{array}$ & $\begin{array}{c}0.547 \\
(0.116)\end{array}$ & $\begin{array}{c}1.254 \\
(0.355)\end{array}$ & $\begin{array}{c}1.220 \\
(0.332)\end{array}$ \\
\hline Log isolation of ethnic group & $\begin{array}{c}0.516 \\
(0.099)\end{array}$ & $\begin{array}{c}0.526 \\
(0.091)\end{array}$ & $\begin{array}{c}0.554 \\
(0.145)\end{array}$ & $\begin{array}{c}0.526 \\
(0.095)\end{array}$ & $\begin{array}{c}0.539 \\
(0.122)\end{array}$ & $\begin{array}{c}0.516 \\
(0.212)\end{array}$ & $\begin{array}{c}0.465 \\
(0.133)\end{array}$ & $\begin{array}{c}0.468 \\
(0.125)\end{array}$ \\
\hline $\begin{array}{l}\text { F statistic } \\
\text { Exogeneity test p-value }\end{array}$ & $\begin{array}{c}23.6 \\
0.034\end{array}$ & $\begin{array}{c}23.4 \\
0.043\end{array}$ & $\begin{array}{c}6.9 \\
0.100\end{array}$ & $\begin{array}{c}34.6 \\
0.011\end{array}$ & $\begin{array}{c}33.1 \\
0.915\end{array}$ & $\begin{array}{c}37.5 \\
0.912\end{array}$ & $\begin{array}{c}15.4 \\
0.014\end{array}$ & $\begin{array}{c}23.0 \\
0.012\end{array}$ \\
\hline & \multicolumn{8}{|c|}{ B. IV results using predicted group sizes and UK in-marriage rates } \\
\hline $\begin{array}{l}\text { Inverse of log ethnic group size } \\
\text { (small groups have larger values) }\end{array}$ & $\begin{array}{c}0.487 \\
(0.132)\end{array}$ & $\begin{array}{c}0.476 \\
(0.123)\end{array}$ & $\begin{array}{c}0.506 \\
(0.091)\end{array}$ & $\begin{array}{c}0.476 \\
(0.105)\end{array}$ & $\begin{array}{c}0.315 \\
(0.185)\end{array}$ & $\begin{array}{c}0.334 \\
(0.179)\end{array}$ & $\begin{array}{l}\text { Insufficient } \\
\text { first stage }\end{array}$ & $\begin{array}{l}\text { Insufficient } \\
\text { first stage }\end{array}$ \\
\hline Log isolation of ethnic group & $\begin{array}{c}0.665 \\
(0.119)\end{array}$ & $\begin{array}{c}0.639 \\
(0.111)\end{array}$ & $\begin{array}{c}0.464 \\
(0.089)\end{array}$ & $\begin{array}{c}0.639 \\
(0.135)\end{array}$ & $\begin{array}{c}0.772 \\
(0.089)\end{array}$ & $\begin{array}{c}0.751 \\
(0.091)\end{array}$ & & \\
\hline F statistic & 35.5 & 34.1 & 13.5 & 20.0 & 40.7 & 29.8 & & \\
\hline Exogeneity test p-value & 0.091 & 0.084 & 0.160 & 0.061 & 0.137 & 0.166 & & \\
\hline
\end{tabular}

Notes: See Tables 2 and 5. 
Table 7: IV estimations with alternative metric designs

\begin{tabular}{|c|c|c|c|c|c|c|c|}
\hline & \multicolumn{5}{|c|}{ Log weighted average overage across all industries } & \multirow{2}{*}{$\begin{array}{l}\text { Log average } \\
\text { of three } \\
\text { largest } \\
\text { overage } \\
\text { ratios for } \\
\text { ethnic group }\end{array}$} & \multirow[b]{2}{*}{$\begin{array}{l}\text { Log largest } \\
\text { overage ratio } \\
\text { for ethnic } \\
\text { group }\end{array}$} \\
\hline & $\begin{array}{l}\text { Baseline } \\
\text { estimation }\end{array}$ & $\begin{array}{l}\text { Using three } \\
\text { largest } \\
\text { industries for } \\
\text { ethnic group }\end{array}$ & $\begin{array}{l}\text { Using total } \\
\text { worker } \\
\text { sample }\end{array}$ & $\begin{array}{c}\text { Excluding } \\
\text { natives from } \\
\text { denominator } \\
\text { shares }\end{array}$ & $\begin{array}{c}\text { Including } \\
\text { rural workers }\end{array}$ & & \\
\hline & $(1)$ & $(2)$ & (3) & (4) & $(5)$ & $(6)$ & $(7)$ \\
\hline & \multicolumn{7}{|c|}{ A. IV results using 1980 ethnic group size and in-marriage rates in United States } \\
\hline $\begin{array}{l}\text { Inverse of log ethnic group size } \\
\text { (small groups have larger values) }\end{array}$ & $\begin{array}{c}0.757 \\
(0.077)\end{array}$ & $\begin{array}{c}0.531 \\
(0.110)\end{array}$ & $\begin{array}{c}0.636 \\
(0.063)\end{array}$ & $\begin{array}{c}0.491 \\
(0.135)\end{array}$ & $\begin{array}{c}0.730 \\
(0.086)\end{array}$ & $\begin{array}{c}0.272 \\
(0.126)\end{array}$ & $\begin{array}{c}0.193 \\
(0.123)\end{array}$ \\
\hline Log isolation of ethnic group & $\begin{array}{c}0.516 \\
(0.099)\end{array}$ & $\begin{array}{c}0.696 \\
(0.091)\end{array}$ & $\begin{array}{c}0.469 \\
(0.104)\end{array}$ & $\begin{array}{c}0.771 \\
(0.113)\end{array}$ & $\begin{array}{c}0.532 \\
(0.097)\end{array}$ & $\begin{array}{c}0.759 \\
(0.087)\end{array}$ & $\begin{array}{c}0.720 \\
(0.107)\end{array}$ \\
\hline $\begin{array}{l}\text { F statistic } \\
\text { Exogeneity test p-value }\end{array}$ & $\begin{array}{c}23.6 \\
0.034\end{array}$ & $\begin{array}{c}23.6 \\
0.019\end{array}$ & $\begin{array}{c}54.4 \\
0.403\end{array}$ & $\begin{array}{c}23.6 \\
0.081\end{array}$ & $\begin{array}{c}23.6 \\
0.040\end{array}$ & $\begin{array}{c}23.6 \\
0.042\end{array}$ & $\begin{array}{c}23.6 \\
0.078\end{array}$ \\
\hline & \multicolumn{7}{|c|}{ B. IV results using predicted group sizes and UK in-marriage rates } \\
\hline $\begin{array}{l}\text { Inverse of log ethnic group size } \\
\text { (small groups have larger values) }\end{array}$ & $\begin{array}{c}0.487 \\
(0.132)\end{array}$ & $\begin{array}{c}0.132 \\
(0.109)\end{array}$ & $\begin{array}{c}0.466 \\
(0.120)\end{array}$ & $\begin{array}{c}0.386 \\
(0.141)\end{array}$ & $\begin{array}{c}0.444 \\
(0.132)\end{array}$ & $\begin{array}{c}0.075 \\
(0.100)\end{array}$ & $\begin{array}{c}0.043 \\
(0.090)\end{array}$ \\
\hline Log isolation of ethnic group & $\begin{array}{c}0.665 \\
(0.119)\end{array}$ & $\begin{array}{c}0.861 \\
(0.125)\end{array}$ & $\begin{array}{c}0.550 \\
(0.177)\end{array}$ & $\begin{array}{c}0.696 \\
(0.130)\end{array}$ & $\begin{array}{c}0.712 \\
(0.122)\end{array}$ & $\begin{array}{c}0.905 \\
(0.104)\end{array}$ & $\begin{array}{c}0.853 \\
(0.088)\end{array}$ \\
\hline F statistic & 35.5 & 35.5 & 10.5 & 35.5 & 35.5 & 35.5 & 35.5 \\
\hline Exogeneity test $\mathrm{p}$-value & 0.091 & 0.022 & 0.107 & 0.687 & 0.055 & 0.239 & 0.464 \\
\hline
\end{tabular}

Notes: See Tables 3 and 5. 
Table 8: IV results with alternative gravity model designs for predicted size

\begin{tabular}{|c|c|c|c|c|c|c|}
\hline & $\begin{array}{l}\text { Baseline } \\
\text { estimation }\end{array}$ & $\begin{array}{l}\text { Including } \\
\text { border in the } \\
\text { gravity model }\end{array}$ & $\begin{array}{c}\text { Including } \\
\text { distance } \\
\text { squared in the } \\
\text { gravity model }\end{array}$ & $\begin{array}{l}\text { Using distance } \\
\text { and population } \\
\text { as instruments }\end{array}$ & $\begin{array}{c}\text { Using distance, } \\
\text { population, and } \\
\text { border as } \\
\text { instruments }\end{array}$ & $\begin{array}{c}\text { Using distance, } \\
\text { population, and } \\
\text { distance } \\
\text { squared as } \\
\text { instruments }\end{array}$ \\
\hline & $(1)$ & $(2)$ & $(3)$ & $(4)$ & $(5)$ & $(6)$ \\
\hline $\begin{array}{l}\text { Inverse of log ethnic group size } \\
\text { (small groups have larger values) }\end{array}$ & $\begin{array}{c}0.487 \\
(0.132)\end{array}$ & $\begin{array}{c}0.483 \\
(0.131)\end{array}$ & $\begin{array}{c}0.483 \\
(0.130)\end{array}$ & $\begin{array}{c}0.522 \\
(0.149)\end{array}$ & $\begin{array}{c}0.524 \\
(0.148)\end{array}$ & $\begin{array}{c}0.522 \\
(0.150)\end{array}$ \\
\hline Log isolation of ethnic group & $\begin{array}{c}0.665 \\
(0.119)\end{array}$ & $\begin{array}{c}0.665 \\
(0.120)\end{array}$ & $\begin{array}{c}0.665 \\
(0.120)\end{array}$ & $\begin{array}{c}0.680 \\
(0.111)\end{array}$ & $\begin{array}{c}0.624 \\
(0.084)\end{array}$ & $\begin{array}{c}0.673 \\
(0.083)\end{array}$ \\
\hline F statistic & 35.5 & 36.2 & 35.8 & 22.2 & 17.0 & 17.0 \\
\hline Exogeneity test p-value & 0.091 & 0.086 & 0.096 & 0.029 & 0.063 & 0.024 \\
\hline Overidentification test $p$-value & & & & 0.174 & 0.283 & 0.394 \\
\hline
\end{tabular}

Notes: See Tables 3 and 5. 
Table 9: Estimations for log yearly income of individual

\begin{tabular}{|c|c|c|c|c|c|c|}
\hline & \multicolumn{3}{|c|}{ Baseline estimation } & \multicolumn{3}{|c|}{ Excluding professionals and $\mathrm{PhDs}$} \\
\hline & $(1)$ & $(2)$ & $(3)$ & $(4)$ & $(5)$ & $(6)$ \\
\hline $\begin{array}{l}\text { Percent of self-employed in } \\
\text { individual's ethnic group (1) }\end{array}$ & $\begin{array}{c}1.145 \\
(0.334)\end{array}$ & & $\begin{array}{c}1.122 \\
(0.335)\end{array}$ & $\begin{array}{c}1.091 \\
(0.347)\end{array}$ & & $\begin{array}{c}1.067 \\
(0.349)\end{array}$ \\
\hline $\begin{array}{l}\text { Share of group that is working in } \\
\text { an individual's industry ( } 2 \text { ) }\end{array}$ & & $\begin{array}{c}0.680 \\
(0.205)\end{array}$ & $\begin{array}{c}0.615 \\
(0.201)\end{array}$ & & $\begin{array}{c}0.624 \\
(0.210)\end{array}$ & $\begin{array}{c}0.562 \\
(0.208)\end{array}$ \\
\hline $\begin{array}{l}\text { Indicator for individual being } \\
\text { self-employed }\end{array}$ & $\begin{array}{c}0.031 \\
(0.002)\end{array}$ & $\begin{array}{c}0.033 \\
(0.004)\end{array}$ & $\begin{array}{c}0.030 \\
(0.002)\end{array}$ & $\begin{array}{c}0.022 \\
(0.002)\end{array}$ & $\begin{array}{c}0.025 \\
(0.004)\end{array}$ & $\begin{array}{c}0.022 \\
(0.002)\end{array}$ \\
\hline $\begin{array}{l}\text { Observations } \\
1 \text { SD change } \mathrm{x} \text { beta }(1) \\
1 \text { SD change } \mathrm{x} \text { beta }(2)\end{array}$ & $\begin{array}{l}1,560,890 \\
0.029\end{array}$ & $\begin{array}{c}1,560,890 \\
0.055\end{array}$ & $\begin{array}{c}1,560,890 \\
0.029 \\
0.050\end{array}$ & $\begin{array}{c}1,286,318 \\
0.028\end{array}$ & $\begin{array}{c}1,286,318 \\
0.050\end{array}$ & $\begin{array}{c}1,286,318 \\
0.027 \\
0.046\end{array}$ \\
\hline
\end{tabular}

Notes: Estimations describe the OLS relationship between log yearly income of individuals and entrepreneurial activity of their ethnic group. Sample is taken from 2000 Census IPUMS. Sample includes native males and immigrant males who migrate after 1968 (effective date of the Immigration Reform Act of 1965), are aged 30-65 in 2000, and have lived in the United States for at least 10 years. Sample excludes workers whose self-employment status is unknown or not applicable, industries without self-employment, and workers living outside of metropolitan areas. Baseline estimation includes fixed effects for the following person-level traits (category counts in parentheses): PUMA geographical location (625), industry (200), native/immigrant (2), age (7), age at immigration for migrants (7), education (3), and English language fluency (2). Regressions cluster standard errors by ethnic group and use IPUMS sample weights. The bottom of the table provides the standard deviation $\mathrm{x}$ beta coefficient for the group-level variables $(0.0255$ for (1), 0.0810 for (2)). Columns 4-6 exclude workers in professional occupations and holders of doctorate degrees. 
Appendix Table 1a: Pairwise correlations of various overage metrics

\begin{tabular}{|c|c|c|c|c|c|c|c|c|c|c|}
\hline & Sample & Metric & (1) & (2) & (3) & (4) & $(5)$ & (6) & (7) & (8) \\
\hline (1) & Self-employed & $\begin{array}{l}\text { Log weighted average overage } \\
\text { ratio across all industries }\end{array}$ & 1 & & & & & & & \\
\hline (2) & & $\begin{array}{l}\text { Log weighted average overage } \\
\text { ratio in three largest industries }\end{array}$ & 0.946 & 1 & & & & & & \\
\hline (3) & & $\begin{array}{l}\text { Log average of three largest } \\
\text { overage ratios for ethnic group }\end{array}$ & 0.923 & 0.961 & 1 & & & & & \\
\hline (4) & & $\begin{array}{l}\text { Log largest overage ratio for } \\
\text { ethnic group }\end{array}$ & 0.859 & 0.927 & 0.966 & 1 & & & & \\
\hline (5) & All workers & $\begin{array}{l}\text { Log weighted average overage } \\
\text { ratio across all industries }\end{array}$ & 0.832 & 0.767 & 0.731 & 0.631 & 1 & & & \\
\hline (6) & & $\begin{array}{l}\text { Log weighted average overage } \\
\text { ratio in three largest industries }\end{array}$ & 0.835 & 0.796 & 0.785 & 0.685 & 0.948 & 1 & & \\
\hline (7) & & $\begin{array}{l}\text { Log average of three largest } \\
\text { overage ratios for ethnic group }\end{array}$ & 0.555 & 0.627 & 0.640 & 0.630 & 0.541 & 0.632 & 1 & \\
\hline (8) & & $\begin{array}{l}\text { Log largest overage ratio for } \\
\text { ethnic group }\end{array}$ & 0.470 & 0.577 & 0.530 & 0.522 & 0.476 & 0.495 & 0.900 & 1 \\
\hline
\end{tabular}

Notes: Table displays correlations between ethnic group overage measures calculated on both self-employment and industry total employment. All correlations are significant at a $5 \%$ level. 
Appendix Table 1b: Pairwise rank correlations of various overage metrics

\begin{tabular}{|c|c|c|c|c|c|c|c|c|c|c|}
\hline & Sample & Metric & (1) & (2) & (3) & (4) & (5) & (6) & (7) & (8) \\
\hline (1) & Self-employed & $\begin{array}{l}\text { Log weighted average overage } \\
\text { ratio across all industries }\end{array}$ & 1 & & & & & & & \\
\hline (2) & & $\begin{array}{l}\text { Log weighted average overage } \\
\text { ratio in three largest industries }\end{array}$ & 0.808 & 1 & & & & & & \\
\hline (3) & & $\begin{array}{l}\text { Log average of three largest } \\
\text { overage ratios for ethnic group }\end{array}$ & 0.588 & 0.789 & 1 & & & & & \\
\hline (4) & & $\begin{array}{l}\text { Log largest overage ratio for } \\
\text { ethnic group }\end{array}$ & 0.569 & 0.760 & 0.971 & 1 & & & & \\
\hline (5) & All workers & $\begin{array}{l}\text { Log weighted average overage } \\
\text { ratio across all industries }\end{array}$ & 0.835 & 0.821 & 0.661 & 0.648 & 1 & & & \\
\hline (6) & & $\begin{array}{l}\text { Log weighted average overage } \\
\text { ratio in three largest industries }\end{array}$ & 0.706 & 0.859 & 0.719 & 0.678 & 0.872 & 1 & & \\
\hline (7) & & $\begin{array}{l}\text { Log average of three largest } \\
\text { overage ratios for ethnic group }\end{array}$ & 0.589 & 0.739 & 0.768 & 0.816 & 0.760 & 0.743 & 1 & \\
\hline (8) & & $\begin{array}{l}\text { Log largest overage ratio for } \\
\text { ethnic group }\end{array}$ & 0.587 & 0.705 & 0.705 & 0.742 & 0.749 & 0.724 & 0.955 & 1 \\
\hline
\end{tabular}

Notes: See Appendix Table 1a. Table displays rank correlations between ethnic group overage measures calculated on both self-employment and industry total employment. All correlations are significant at a 5\% level. 